OPEN ACCESS

Edited by:

Phila Raharivelomanana, University of French Polynesia, French

Polynesia

Reviewed by:

Dimitrios Fanourakis,

Technological Educational Institute

of Crete, Greece

Mirza Hasanuzzaman,

Sher-e-Bangla Agricultural University,

Bangladesh

*Correspondence:

In-Jung lee

ijlee@knu.ac.kr

Elham Ahmed Kazerooni elham.ghasemi.k@gmail.com

Specialty section:

This article was submitted to

Plant Breeding,

a section of the journal

Frontiers in Plant Science

Received: 31 August 2020 Accepted: 03 March 2021

Published: 01 April 2021

Citation:

Park H-S, Kazerooni EA, Kang S-M, Al-Sadi AM and Lee I-J

(2021) Melatonin Enhances

the Tolerance and Recovery Mechanisms in Brassica juncea (L.)

Czern. Under Saline Conditions.

Front. Plant Sci. 12:593717.

doi: $10.3389 / \mathrm{fp} / \mathrm{s} .2021 .593717$

\section{Melatonin Enhances the Tolerance and Recovery Mechanisms in Brassica juncea (L.) Czern. Under Saline Conditions}

\author{
Hee-Soon Park', Elham Ahmed Kazerooni ${ }^{*}$, Sang-Mo Kang ${ }^{1}$, \\ Abdullah Mohammed Al-Sadi ${ }^{2}$ and In-Jung Lee ${ }^{1 *}$
}

${ }^{1}$ School of Applied Biosciences, Kyungpook National University, Daegu, South Korea, ${ }^{2}$ Department of Crop Sciences, College of Agricultural and Marine Sciences, Sultan Qaboos University, Muscat, Oman

Melatonin has been recently known to stimulate plant growth and induce protective responses against different abiotic stresses. However, the mechanisms behind exogenous melatonin pretreatment and restoration of plant vigor from salinity stress remain poorly understood. The present study aimed to understand the effects of exogenous melatonin pretreatment on salinity-damaged green mustard (Brassica juncea L. Czern.) seedlings in terms of oxidative stress regulation and endogenous phytohormone production. Screening of several melatonin concentrations $(0,0.1,1$, 5 , and $10 \mu \mathrm{M}$ ) on mustard growth showed that the $1 \mu \mathrm{M}$ concentration revealed an ameliorative increase of plant height, leaf length, and leaf width. The second study aimed at determining how melatonin application can recover salinity-damaged plants and studying its effects on physiological and biochemical parameters. Under controlled environmental conditions, mustard seedlings were irrigated with distilled water or $150 \mathrm{mM}$ of $\mathrm{NaCl}$ for 7 days. This was followed by $1 \mu \mathrm{M}$ of melatonin application to determine its recovery impact on the damaged plants. Furthermore, several physiological and biochemical parameters were examined in stressed and unstressed seedlings with or without melatonin application. Our results showed that plant height, leaf length/width, and stem diameter were enhanced in 38-day-old salinitystressed plants under melatonin treatment. Melatonin application obviously attenuated salinity-induced reduction in gas exchange parameters, relative water content, and amino acid and protein levels, as well as antioxidant enzymes, such as superoxide dismutase and catalase. $\mathrm{H}_{2} \mathrm{O}_{2}$ accumulation in salinity-damaged plants was reduced by melatonin treatment. A decline in abscisic acid content and an increase in salicylic acid content were observed in salinity-damaged seedlings supplemented with melatonin. Additionally, chlorophyll content decreased during the recovery period in salinitydamaged plants by melatonin treatment. This study highlighted, for the first time, the recovery impact of melatonin on salinity-damaged green mustard seedlings. It demonstrated that exogenous melatonin supplementation significantly improved the physiologic and biochemical parameters in salinity-damaged green mustard seedlings.

Keywords: salinity, melatonin, antioxidant enzymes, photosynthesis, amino acids, phytohormones, green mustard 


\section{INTRODUCTION}

Environmental problems, such as drought, salinity, and the rising global temperature, cause considerable restraints in agricultural production and threaten food security worldwide (Tester and Langridge, 2010). Approximately $20 \%$ of farmlands are affected by salt globally, and each year, this number steadily increases because of natural causes or irrigation practices, as well as excessive fertilization and plowing, which result in a decreased or no plant yield (Deinlein et al., 2014; Ke et al., 2016). High salt concentrations generate ion toxicity (mainly sodium ions), osmotic stress, and oxidative damage, and suppress many biochemical and molecular processes (Chen et al., 2018). Genetic improvement is a useful strategy for crop enhancement (Ke et al., 2016; Zhu et al., 2016); however, due to the complex and controversial issues that are connected to transgenic (GM) crops (Raman, 2017), a substitute strategy for improving stress tolerance and prolonging leaf endurance and longevity can result in important agricultural applications.

Melatonin ( $\mathrm{N}$-acetyl-5-methoxytryptamine) is an amphiphilic low-molecular-weight hormone with an indolic structure (Arnao and Hernández-Ruiz, 2014; Campos et al., 2019). Melatonin was originally identified in bovine pineal glands in 1958 (Chowdhury et al., 2008). This biomolecule influences several biological functions, such as the sleep-wake cycle, bone metabolism, innate immune system, seasonal reproduction, and emotional behavior (Tan et al., 2010; Carrillo-Vico et al., 2013; Shi et al., 2015a). There has been great progress in understanding melatonin's role in plants since its existence was initially reported in vascular plants in 1995 (Dubbels et al., 1995; Van Tassel et al., 1995). Several studies on melatonin have proposed its possible physiologic actions in plants, including growth-stimulating activity, seed germination, flowering, and rooting, thereby acting in the same manner as auxin and indole-3-acetic acid (Arnao and Hernández-Ruiz, 2014; Wei et al., 2015). Endogenously synthesized melatonin performs a migratory role in coping with biotic/abiotic stresses. It confers stress tolerance toward heavy metals, ultraviolet radiation, salt, drought, and temperature fluctuations (Reiter et al., 2015; Nawaz et al., 2016). Melatonin also promotes the activity of scavenging enzymes, which leads to reducing and eliminating internal and environmental oxidative damages (ROS) (Arnao and Hernández-Ruiz, 2015; Li et al., 2015). It has been reported that pretreatment with exogenous melatonin preserves plant integrity; plays a recovery role in plants under stressful conditions, such as drought, salinity, heat, chemicals, cold, and oxidation; and retards natural aging and senescence (Li et al., 2012; Shi et al., 2015b; Zhang et al., 2015).

Green mustard (Brassica juncea L. Czern.) is widely consumed all over the world, especially in Asia, as food and spice (Whitley, 2013). This species of the family Brassicaceae has been cultivated due to its nutritional and economic values (Ashraf and Iram, 2005). The leaves and seeds of this plant have been traditionally used because of its medicinal values mainly for internal and external diseases, such as rheumatism, skin disease, and inflammation (Lee et al., 2007). Furthermore, several studies have characterized the antioxidant, anti-cancer, anti-diabetic, and antimicrobial effects of green mustard (Sim et al., 2008; Jo et al., 2018). In case of salinity tolerance in the Brassicaceae family, B. juncea is relatively sensitive. Its growth and yield can be markedly reduced under stressful conditions, such as salinity, drought, and high temperature (Ashraf and Iram, 2005). Therefore, developing salt tolerance in this species would be economically valuable.

Salt stress reduction through exogenous melatonin pretreatment has already been extensively studied (Wang et al., 2016; Li et al., 2017; Ke et al., 2018); however, only a few have investigated the effects of melatonin on salt stress recovery. To fill this gap, we conducted this study to evaluate the effect of melatonin on the recovery of salt-damaged green mustard seedlings. Two specific objectives were set. First, we aimed to characterize the appropriate melatonin concentration that was efficient against salinity-damaged plants. Second, we intended to investigate how exogenous melatonin application affects the physiologic and biochemical characteristics of salinity-damaged plants by presenting growth changes, photosynthetic rate, plant hormone contents, amino acid contents, etc.

\section{MATERIALS AND METHODS}

\section{Selection of the Appropriate Melatonin Concentration}

Green mustard seeds were provided by Danong Korea Ltd., Gyeonggi-do, South Korea. The seeds were surface-sterilized in $2.5 \%$ sodium hypochlorite and tested for viability, according to a method previously described by Ke et al. (2018). The germinated seeds were sown in plastic pot trays $(28 \mathrm{~cm} \times 54 \mathrm{~cm})$ filled with horticultural soil (Shinsung Mineral Co., Ltd., South Korea). Then, two to three seeds were planted in each pot. The mustard seedlings were pre-cultivated under natural light in a greenhouse at Kyungpook National University, Daegu, South Korea $\left(35.53^{\prime \circ} \mathrm{N}, 128.36^{\circ} \mathrm{E}\right)$, with $46.7 \%$ relative humidity (RH) and $25^{\circ} \mathrm{C} / 19^{\circ} \mathrm{C}$ (day/night) temperature, and the seedlings were watered daily. Furthermore, 3-weekold seedlings with uniform sizes were transferred to pots $(10 \mathrm{~cm} \times 10 \mathrm{~cm})$ and subjected to different treatments. Precultivated seedlings were kept for 2 days to allow them to acclimatize. Then, all mustard seedlings were randomly divided into two groups: (i) normal control, grown with only distilled water $(100 \mathrm{~mL} / \mathrm{plant})$; and (ii) salinity treatment, irrigated with $150 \mathrm{mM} \mathrm{NaCl}(100 \mathrm{~mL} /$ plant$)$. Each treatment contained a triplicate of 15 plants each. Each group was treated for 7 days. Afterward, the salinity-stressed seedlings were treated with 0 , $0.1,1,5$, and $10 \mu \mathrm{M}$ melatonin $(100 \mathrm{~mL} / \mathrm{plant}$, once a day) on their roots for 16 days. The melatonin (ChemScene LLC., Monmouth Junction, NJ, United States) solution (10 $\mu \mathrm{M}$, stock) was prepared by dissolving the solute in distilled water $(2.32 \mathrm{mg} \times 1,000 \mathrm{~mL})$, followed by dilution with distilled water to prepare different concentrations. Plants of each concentration were measured for several plant growth characteristics. Plant growth parameters, such as plant height, leaf length, and leaf width were measured after day 4 (4DAT), day 8 (8DAT), day 12 (12DAT), and day 
16 (16DAT) of treatment. Moreover, the $1 \mu \mathrm{M}$ melatonin concentration was found to be the most optimal concentration for further studies.

\section{Effect of Exogenous Melatonin on Salinity-Damaged Green Mustard Plant Material and Growth Conditions}

The experiments were performed from December 2018 to February 2019 in a growth chamber at Kyungpook National University. The plants were grown under the aforementioned conditions. Moreover, green mustard seeds were planted in plastic pot trays containing horticultural soil (Shinsung Mineral Co., Ltd, South Korea). Seedlings of similar size were selected after 3 weeks and then transferred to pots $(10 \mathrm{~cm} \times 10 \mathrm{~cm})$. During the experiment, the temperature was maintained at a constant $22^{\circ} \mathrm{C} / 20^{\circ} \mathrm{C}$ (day/night) level, with an $\mathrm{RH}$ of $60 \%$ and a light intensity of approximately $200 \mu \mathrm{mol} \mathrm{m}^{-2} \mathrm{~s}^{-1}$.

\section{Salinity Stress Pretreatments}

In this part of the study, 2 days after transplanting, 3-weekold seedlings were subjected to different treatments. They were divided into two groups: the normal control group, irrigated with distilled water $(\mathrm{DW})(100 \mathrm{~mL})$; and the salinity treatment group, irrigated with $150 \mathrm{mM} \mathrm{NaCl}(100 \mathrm{~mL})$. Each group was treated for 7 days, and after which, the groups of unstressed and salinity-stressed seedlings were subdivided into two groups with an equal number of seedlings. This contributed to the formation of four experimental groups: (1) normal control, irrigated with DW alone $(100 \mathrm{~mL})$; (2) normal control, irrigated with solution containing $1 \mu \mathrm{M}$ melatonin $(100 \mathrm{~mL})$; (3) salinity pretreated $(150 \mathrm{mM} \mathrm{NaCl})$, irrigated with $\mathrm{DW}(100 \mathrm{~mL})$; and (4) salinity pretreated, (150 $\mathrm{mM} \mathrm{NaCl})$, irrigated with solution containing $1 \mu \mathrm{M}$ melatonin $(100 \mathrm{~mL})$. Each treatment was performed in triplicate with 12 plants each. The mustard seedlings were treated for 8 days, and sampling was performed at days 4 and 8 in each treatment. After recording the chlorophyll content, the harvested samples (shoots and leaves) were either freshly used or rapidly deactivated in liquid nitrogen and stored at $-80^{\circ} \mathrm{C}$.

\section{Assessment of Plant Growth Characteristics and Chlorophyll Content}

To investigate the effects of each treatment on green mustard seedlings, several plant growth parameters were measured. These parameters included plant height, stem diameter, and leaf length/width, which were recorded over a period of 8 days, specifically on day 0 (0DAT), day 4 (4DAT), and day 8 (8DAT). A digital Vernier caliper and a ruler were used to measure stem diameter and plant height, respectively. For estimating the leaf area (length and width), a fully expanded leaf (beneath the growing point) from each plant was selected and measured using a ruler. Chlorophyll content in leaves was examined using a portable CCM-300 Chlorophyll Content Meter (ADC BioScientific Ltd., Herts, England). Each treatment had three replicates.

\section{Analysis of Photosynthetic Gas Exchange Parameters}

The photosynthetic rate, stomatal conductance, and transpiration rate were determined using an LCpro $\mathrm{T}$ portable photosynthetic assay system (ADC Bioscientific Ltd., Herts, England). The plants were constantly exposed to photosynthetically active radiation (PAR) $1,500 \mu \mathrm{mol} \mathrm{m} \mathrm{m}^{-2} \mathrm{~s}^{-1}$. The topmost fully expanded leaf from each group was selected at the vegetative stage and measured on day 0 (0DAT), day 4 (4DAT), and day 8 (8DAT). The photosynthetic parameters were taken within the chamber between 9:00 and 11:00 AM, and each treatment had three replicates.

\section{Determination of Leaf RWC}

Relative water content (RWC) was measured in the stressed and unstressed plants following the method previously described by Ahmad et al. (2019). This measurement was conducted for each treatment on day 4 (4DAT) and day 8 (8DAT). The fresh weight (FW) of the fourth leaf (counting from the bottom) of mustard seedlings was immediately recorded after harvesting (between 5:00 and 6:00 PM). Then, the leaf segments were made to float in DW in a closed container at $25^{\circ} \mathrm{C}$ for $15 \mathrm{~h}$ in the dark, and its saturated weight (SW) was determined. After that, the leaf samples were kept in the oven at $70^{\circ} \mathrm{C}$ for $48 \mathrm{~h}$ to obtain the dry weight $(\mathrm{DW})$. Finally, the relative water concentration was estimated according to the formula RWC $(\%)=(\mathrm{FW}-\mathrm{DW}) /(\mathrm{SW}-$ DW) $\times 100$. Each treatment had three replicates.

\section{Quantitation of ABA Content}

Abscisic acid (ABA) content was analyzed according to a previously described method (Qi et al., 1998; Kim et al., 2014). Freeze-dried sample of mustard leaves was ground using a mortar and pestle. The ground sample (approximately $0.1 \mathrm{~g}$ ) was extracted with $10 \mathrm{~mL}$ of extraction solution. The filtered extract was concentrated, then dissolved in $5 \mathrm{~mL}$ of sodium hydroxide $(1 \mathrm{~N} \mathrm{NaOH})$, and washed three times with dichloromethane $\left(10 \mathrm{~mL} \mathrm{CH}_{2} \mathrm{Cl}_{2}\right)$ to eliminate the lipophilic materials. The $\mathrm{pH}$ of the aqueous phase was adjusted to 3.5 using hydrochloric acid $(6 \mathrm{~N} \mathrm{HCl})$. Then, ethyl acetate was added to it and mixed by vortexing. The supernatant, ethyl acetate extract, was evaporated to dryness and dissolved in phosphate buffer ( $\mathrm{PH}$ 8.0) to remove phenolic compounds. PVPP (polyvinylpolypyrrolidone) was added to the extracted solution (phosphate buffer) and kept on a shaker for $40 \mathrm{~min}$ at $150 \mathrm{rpm}$. The $\mathrm{pH}$ of the phosphate buffer was brought to 2.5 and partitioned into ethyl acetate. The ethyl acetate extract was evaporated to dryness. The dried residue was dissolved in dichloromethane $\left(\mathrm{CH}_{2} \mathrm{Cl}_{2}\right)$, followed by passing through a silica cartridge (Sep-Pak; Water Associates, Milford, MA, United States) pre-washed with dichloromethane and $\mathrm{MeOH}$ diethylether $\left(\mathrm{C}_{5} \mathrm{H}_{14} \mathrm{O}_{2}\right)$. Finally, the extract was dried with nitrogen gas $\left(\mathrm{N}_{2}\right)$, and diazomethane $\left(\mathrm{CH}_{2} \mathrm{~N}_{2}\right)$ was added to it for methylation. ABA content was quantified through GC-MS (Agilent 6890N Gas Chromatograph, Santa Clara, CA, United States). A software (ThermoQuset, Manchester, United Kingdom) was used to observe the responses to ions [m/e of 162 and 190 for Me-ABA and 166 and 194 for Me- $\left.\left({ }^{2} \mathrm{H}_{6}\right)-\mathrm{ABA}\right]$. 


\section{Quantitation of SA Content}

Salicylic acid (SA) content was analyzed according to a previously described method (Enyedi et al., 1992; Seskar et al., 1998). Freezedried sample of mustard leaves was ground to a fine powder and approximately $0.1 \mathrm{~g}$ of it was extracted with methanol (90 and $100 \%$ ) by centrifuging $(12,000 \mathrm{rpm}$ for $15 \mathrm{~min}$ at $\left.4^{\circ} \mathrm{C}\right)$. The combined methanol extracts were vacuum-dried. The dried residue was dissolved in 5\% trichloroacetic acid (TCA) and centrifuged at $10,000 \mathrm{rpm}$ for $10 \mathrm{~min}$. The supernatant was partitioned with ethyl acetate/cyclopentane/isopropanol $(49.5: 49.5: 1, \mathrm{v} / \mathrm{v})$. The top layer of the aqueous solution was dried and used for SA quantification through high-performance liquid chromatography.

\section{Measurement of Amino Acid Content}

Quantification of amino acid content was carried out according to the described method of Waqas et al. (2015). Approximately $50 \mathrm{mg}$ of the freeze-dried sample was hydrolyzed in the presence of hydrochloric acid $(6 \mathrm{~N} \mathrm{HCl}, 1 \mathrm{~mL})$ for $24 \mathrm{~h}$ at $110^{\circ} \mathrm{C}$. Then, the extraction was concentrated and dried with vacuum at $80^{\circ} \mathrm{C}$ for $24 \mathrm{~h}$. After that, the residue was diluted with deionized water $(2 \mathrm{~mL})$ and evaporated two times. Finally, the concentrated residue was dissolved with hydrochloric acid $(0.02 \mathrm{~N}$ $\mathrm{HCl}, 1 \mathrm{~mL}$ ) and the mixture was passed through a $0.45-\mu \mathrm{m}$ filter membrane. The solution was analyzed using a Hitachi L-8900 amino acid analyzer (Hitachi High-Technologies Corporation, Tokyo, Japan). Each treatment had three replicates.

\section{Measurement of Soluble Protein Content}

Soluble protein content subjected to different treatments was quantified following the method previously described by Ashraf and Iram (2005). Fresh plant leaves $(0.1 \mathrm{~g})$ were ground to a fine powder using a mortar and pestle, and then mixed with $1 \mathrm{~mL}$ of phosphate buffer (50 mM, pH 7.0). The mixture was centrifuged at $10,000 \mathrm{rpm}$ for $10 \mathrm{~min}$ at $4^{\circ} \mathrm{C}$. Subsequently, the supernatant was collected and treated with the appropriate reagent, and the optical density was measured at $595 \mathrm{~nm}$. Protein content was estimated in all the enzymatic preparations using the Bradford method (Bradford, 1976) with bovine serum albumin as standard.

\section{Determination of Enzymatic and Non-enzymatic Antioxidant Activity}

Fresh leaf samples $(0.1 \mathrm{~g})$ were homogenized with $1 \mathrm{~mL}$ of icecold $50 \mathrm{mM}$ phosphate buffer (pH 7.0, 1 mM EDTA, 1\% PVP) and kept in an incubator at $4^{\circ} \mathrm{C}$ for $10 \mathrm{~min}$. Subsequently, the mixture was centrifuged at $10,000 \mathrm{rpm}$ for $10 \mathrm{~min}$ at $4^{\circ} \mathrm{C}$. The supernatant was used for determining superoxide dismutase (SOD) and catalase (CAT) activity. SOD activity was measured using a SOD Assay Kit-WST (Dojindo Co., Ltd., Kumamoto, Japan). CAT activity was evaluated using the Amplex ${ }^{\mathrm{TM}}$ Red Catalase Assay Kit (Thermo Fisher Scientific Korea Co., Ltd., Gangnam$\mathrm{gu}$, Seoul), according to the manufacturer's instruction. DPPH radical scavenging activities, flavonoid and total phenolic content were analyzed by the method of Adhikari et al. (2018). The mixture activity and absorbance were measured using the Multiskan ${ }^{\mathrm{TM}}$ GO UV/Vis microplate spectrophotometer (Thermo Fisher Scientific, Waltham, MA, United States) at a selected wavelength.

\section{Visualization of ROS by Staining}

Accumulation of ROS components was determined based on the DAB (3,3-diaminobenzidine) staining method (ThordalChristensen et al., 1997; Mishra et al., 2017). The third leaves were cut off on day 4 (4DAT) and day 8 (8DAT), and stained in the DAB solution $\left(1 \mathrm{mg} \mathrm{ml}^{-1}, \mathrm{pH}\right.$ 3.8). DAB staining and vacuum filtration were carried out for $12 \mathrm{~h}$ in darkness, followed by de-colorization of the stained leaves using absolute ethanol for $10 \mathrm{~min}$ in a boiling water bath. The leaves were then kept in $60 \%$ glycerol for 1-2 min. Three leaves were used for each treatment.

\section{Determination of ROS Content $\left(\mathrm{H}_{2} \mathrm{O}_{2}\right)$}

$\mathrm{H}_{2} \mathrm{O}_{2}$ level subjected to several treatments was determined according to a previously described method (Jana and Choudhuri, 1982; Tsai et al., 2005). Third leaves of green mustard were collected on day 4 (4DAT) and day 8 (8DAT) and kept in a freezer at $-80^{\circ} \mathrm{C}$. The frozen leaves were ground with liquid nitrogen using a mortar and pestle. The ground sample $(0.3 \mathrm{~g})$ was homogenized with $3 \mathrm{~mL}$ of ice-cold phosphate buffer (50 mM, $1 \mathrm{mM}$ EDTA, 1\% PVP, pH 7.0) and centrifuged at $13,000 \mathrm{rpm}$ for $20 \mathrm{~min}$. The supernatant $(2 \mathrm{~mL})$ was mixed with $1 \mathrm{~mL}$ of $20 \%(\mathrm{v} / \mathrm{v}) \mathrm{H}_{2} \mathrm{SO}_{4}$ containing $0.1 \%$ titanium chloride, and the mixture was centrifuged at $13,000 \mathrm{rpm}$ for $20 \mathrm{~min}$. The supernatant intensity was measured at $410 \mathrm{~nm}$ using the T60 UV-Vis spectrophotometer (PG Instruments Ltd., Wibtoft, United Kingdom). $\mathrm{H}_{2} \mathrm{O}_{2}$ level was determined using an extinction coefficient of $0.28 \mu \mathrm{mol}^{-1} \mathrm{~cm}^{-1}$. Three leaves were used for each treatment.

\section{Statistical Analysis}

All experimental data were processed using ANOVA and Duncan's multiple range test $(p<0.05)$ to examine the significant differences between the mean values. It was run with three biological replicates using Microsoft Excel 2017 and SAS statistical software (version 9.4, SAS Institute, Cary, NC, United States).

\section{RESULTS}

\section{Effects of Several Melatonin Concentrations on the Growth of Green Mustard Seedlings Under Salt Stress}

The salinity treatment led to decreased plant height, leaf length, and leaf width, compared with the control. However, when salinity-stressed plants received several concentrations of melatonin $(0,0.1,1,5$, and $10 \mu \mathrm{M})$, they generally showed alleviation of salt stress in comparison with salinity-stressed plants alone (Figure 1). Treatment with a lower concentration of melatonin $(0.1 \mu \mathrm{M})$ showed no remarkable change, compared with salinity-stressed plants; or with a higher concentration of melatonin $(10 \mu \mathrm{M})$, compared with salinity-stressed plants alone. 


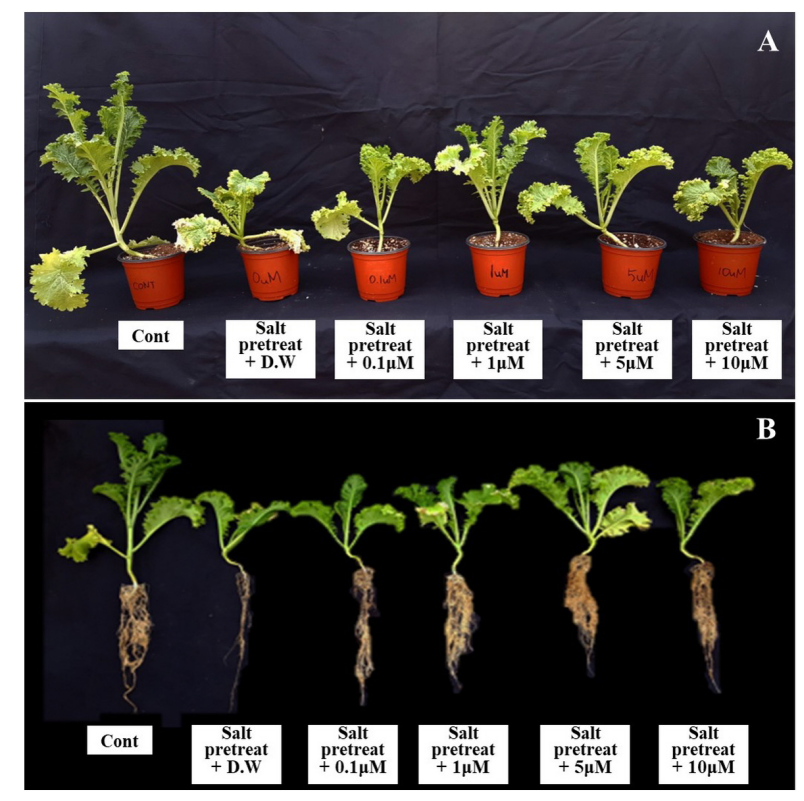

FIGURE 1 | Effect of various melatonin concentrations on the growth of salt-stressed green mustard seedlings (A,B). Treatment: control + water, $150 \mathrm{mM}$ salt pre-treatment + water, $150 \mathrm{mM}$ salt pre-treatment $+0.1 \mu \mathrm{M}$ melatonin, $150 \mathrm{mM}$ salt pre-treatment $+1 \mu \mathrm{M}$ melatonin, $150 \mathrm{mM}$ salt pre-treatment $+5 \mu \mathrm{M}$ melatonin, $150 \mathrm{mM}$ salt pre-treatment $+10 \mu \mathrm{M}$ melatonin.

However, salinity-stressed plants at a melatonin concentration of $1 \mu \mathrm{M}$ revealed increased plant height (4.3\%), leaf length $(13 \%)$, and leaf width $(11.2 \%)(p<0.05)$ in contrast to salinitystressed plants alone (Figure 2). These values showed that $1 \mu \mathrm{M}$ of melatonin attenuated the suppressive effect of salinity stress on plant growth. Our findings indicate the necessity of choosing the appropriate melatonin concentration prior to application on crops.

\section{Recovery Effect of Exogenous Melatonin on Green Mustard Seedlings Under Salinity Stress}

Effects of Melatonin on Plant Growth Characteristics

Mustard seedlings were grown and supplemented with $1 \mu \mathrm{M}$ melatonin concentration to examine the effects of exogenous melatonin on plant growth parameters. As shown in Table 1, no significant difference was observed between melatonintreated and -untreated seedlings under normal conditions after 8 days. Salinity stress led to decreased plant height (34\%), leaf length (32\%), leaf width (34\%), and stem diameter $(20 \%)$ $(p<0.05)$. The growth of salinity-stressed plants with or without melatonin was inhibited, compared with unstressed plants. However, in melatonin-treated seedlings, plant height (10\%), leaf length (16\%), leaf width (20\%), and stem diameter (13\%) were higher than melatonin-untreated seedlings under salinitystressed conditions. Our results showed that root application of $1 \mu \mathrm{M}$ of melatonin improved the plant growth parameters under salinity stress (150 mM NaCl) conditions (Table 1 and Figure 3).
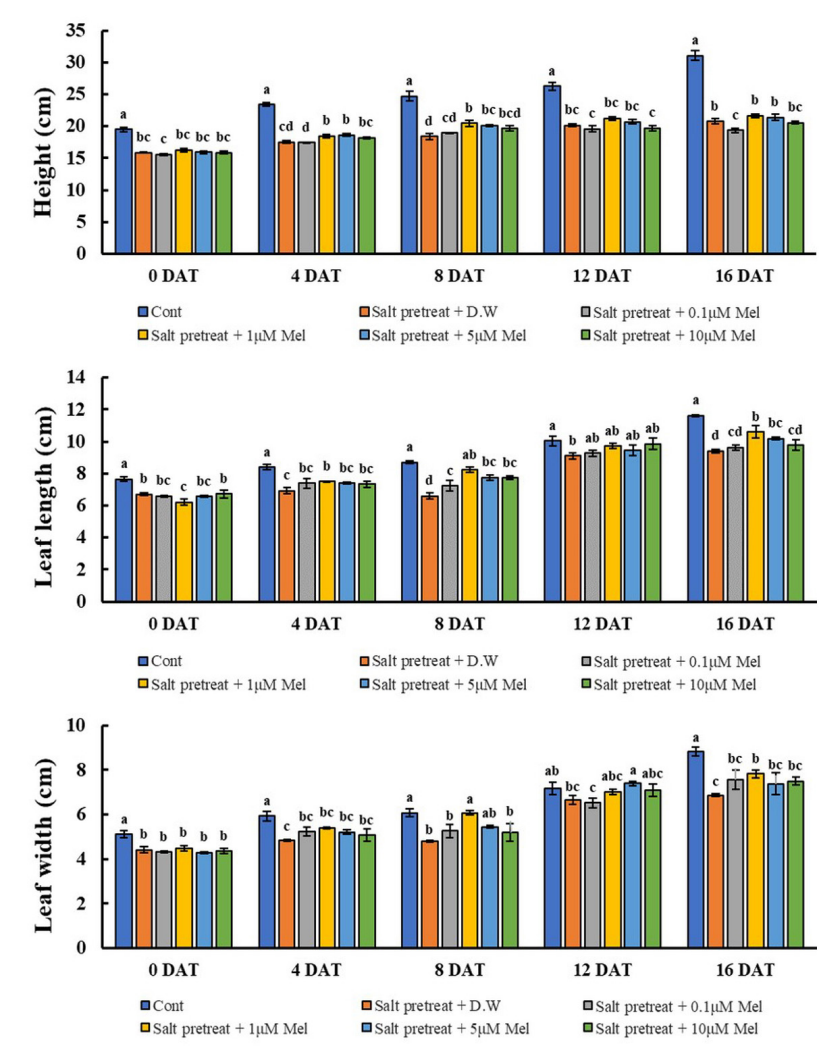

FIGURE 2 | Effect of various melatonin concentrations on the growth of salt-stressed green mustard seedlings. The results were calculated from data for 0 (ODAT), 4 (4DAT), 8 (DAT), 12 (12DAT), and 16 (16DAT) days. Treatment: control + water, $150 \mathrm{mM}$ salt pre-treatment + water, $150 \mathrm{mM}$ salt pre-treatment $+0.1 \mu \mathrm{M}$ melatonin, $150 \mathrm{mM}$ salt pre-treatment $+1 \mu \mathrm{M}$ melatonin, $150 \mathrm{mM}$ salt pre-treatment $+5 \mu \mathrm{M}$ melatonin, $150 \mathrm{mM}$ salt pre-treatment $+10 \mu \mathrm{M}$ melatonin. Values show the means $\pm \mathrm{SE}(n=3)$ and significant differences at $p<0.05$ in accordance with Duncan's multiple range tests.

\section{Effects of Melatonin on Chlorophyll Content}

As shown in Figure 4, no significant difference was observed between melatonin-treated and -untreated seedlings under normal conditions after 4 days (4DAT) and 8 days (8DAT). Salinity stress resulted in rapidly increasing chlorophyll content, compared with water-treated seedlings. Chlorophyll content was higher in salinity-stressed group plants by $36.5 \%$ (4DAT) and $36.4 \%$ (8DAT), compared with water-treated group $(p<0.05)$. Visual observations of salinity-stressed plants showed a deeper green leaf color. The root application of melatonin decreased the chlorophyll content by $11 \%$ in salinity-stressed green mustard seedlings. Our findings revealed that root application of $1 \mu \mathrm{M}$ melatonin recovered the chlorophyll content under salinity stress (150 mM NaCl) conditions (Figure 4).

\section{Effects of Melatonin on Gas Exchange Parameters}

A reduction in photosynthetic parameters was observed under salinity treatment $(150 \mathrm{mM})$. Stomatal conductance, transpiration rate, and photosynthetic rate decreased significantly in salinity-stressed plants by 83,67 , and 74\% ( $p<0.05)$, 
TABLE 1 | The Effect of melatonin with/without salt stress on growth parameters in green mustard seedlings.

\begin{tabular}{lcccc}
\hline Treatment & $\begin{array}{c}\text { Height } \\
\mathbf{( c m})\end{array}$ & $\begin{array}{c}\text { Leaf length } \\
\mathbf{( c m})\end{array}$ & $\begin{array}{c}\text { Leaf width } \\
\mathbf{( c m )}\end{array}$ & $\begin{array}{c}\text { Stem } \\
\text { diameter } \\
(\mathbf{c m})\end{array}$ \\
\hline 0 DAT & & & & \\
Cont & $15.3 \pm 0.4^{\mathrm{a}}$ & $10.9 \pm 0.2^{\mathrm{a}}$ & $7.9 \pm 0.1^{\mathrm{a}}$ & $5.2 \pm 0.1^{\mathrm{a}}$ \\
Mel & $15.3 \pm 0.1^{\mathrm{a}}$ & $9.8 \pm 0.5^{\mathrm{b}}$ & $7.6 \pm 0.1^{\mathrm{a}}$ & $4.9 \pm 0.0^{\mathrm{b}}$ \\
Salt pretreated Cont & $10.1 \pm 0.4^{\mathrm{b}}$ & $7.1 \pm 0.2^{\mathrm{c}}$ & $5.2 \pm 0.1^{\mathrm{b}}$ & $4.1 \pm 0.1^{\mathrm{c}}$ \\
Salt pretreated Mel & $10.0 \pm 0.1^{\mathrm{b}}$ & $6.9 \pm 0.1^{\mathrm{c}}$ & $5.1 \pm 0.1^{\mathrm{b}}$ & $4.0 \pm 0.0^{\mathrm{c}}$ \\
4 DAT & & & & \\
Cont & $19.1 \pm 0.4^{\mathrm{a}}$ & $12.8 \pm 0.4^{\mathrm{a}}$ & $8.4 \pm 0.3^{\mathrm{a}}$ & $6.1 \pm 0.1^{\mathrm{a}}$ \\
Mel & $19.4 \pm 0.8^{\mathrm{a}}$ & $13.0 \pm 0.3^{\mathrm{a}}$ & $8.7 \pm 0.1^{\mathrm{a}}$ & $6.2 \pm 0.1^{\mathrm{a}}$ \\
Salt pretreated Cont & $11.8 \pm 0.2^{\mathrm{c}}$ & $8.3 \pm 0.2^{\mathrm{c}}$ & $5.4 \pm 0.1^{\mathrm{c}}$ & $4.5 \pm 0.1^{\mathrm{c}}$ \\
Salt pretreated Mel & $13.0 \pm 0.3^{\mathrm{b}}$ & $9.4 \pm 0.3^{\mathrm{b}}$ & $6.3 \pm 0.1^{\mathrm{b}}$ & $4.9 \pm 0.1^{\mathrm{b}}$ \\
8 DAT & & & & \\
Cont & $19.2 \pm 0.4^{\mathrm{b}}$ & $13.5 \pm 0.5^{\mathrm{a}}$ & $8.5 \pm 0.1^{\mathrm{a}}$ & $6.9 \pm 0.2^{\mathrm{a}}$ \\
Mel & $20.2 \pm 0.5^{\mathrm{a}}$ & $14.1 \pm 0.2^{\mathrm{a}}$ & $8.4 \pm 0.1^{\mathrm{a}}$ & $7.0 \pm 0.1^{\mathrm{a}}$ \\
Salt pretreated Cont & $13.6 \pm 0.1^{\mathrm{d}}$ & $9.4 \pm 0.1^{\mathrm{c}}$ & $6.1 \pm 0.1^{\mathrm{c}}$ & $5.2 \pm 0.2^{\mathrm{b}}$ \\
Salt pretreated Mel & $14.9 \pm 0.3^{\mathrm{c}}$ & $10.9 \pm 0.3^{\mathrm{b}}$ & $7.3 \pm 0.2^{\mathrm{b}}$ & $5.9 \pm 0.2^{\mathrm{b}}$
\end{tabular}

The data were calculated from data for 0 (ODAT), 4 (4DAT), and 8 (8DAT) days. Treatment: control + water, control + $1 \mu \mathrm{M}$ melatonin, $150 \mathrm{mM}$ salt pretreatment + water, $150 \mathrm{mM}$ salt pre-treatment $+1 \mu \mathrm{M}$ melatonin. Values indicate the means $\pm S E(n=3)$. Letters represent significant differences at $p<0.05$ in accordance with Duncan's multiple range tests.

respectively, compared with control plants (Figure 5). However, exogenous melatonin $(1 \mu \mathrm{M})$ alleviated stress in plants grown under saline conditions. Notable enhancement in stomatal conductance (51\%), photosynthetic rate (79\%), and transpiration rate $(32 \%)$ was detected when seedlings subjected to $150 \mathrm{mM}$ salinity stress were treated with $1 \mu \mathrm{M}$ melatonin over 8 days $(p<0.05)$ (Figure 5). Interestingly, the transpiration rate was higher on day $4(9.18 \%)$ than on day 8 in response to melatoninsalt treatment. The decreased gas exchange parameters were alleviated through melatonin treatment in stressed plants over 8 days. Melatonin application particularly lowered stomatal conductance, photosynthetic rate, and transpiration rate in unstressed plants. This result indicated that root application of melatonin attenuated the salinity-induced reduction of photosynthetic parameters.

\section{Effects of Melatonin on Leaf RWC}

As shown in Figure 6, exogenous melatonin application caused a reduction in RWC of control plants on day 4 (4DAT) and day 8 (8DAT). A significant decrease (16\%) in RWC of salinitystressed seedlings was observed, compared with normal seedlings (Figure 6). On another note, there was a slight improvement (4.3\%) in RWC when seedlings were exposed to $1 \mu \mathrm{M}$ melatonin treatment and $150 \mathrm{mM}$ salt stress over 8 days. These values showed that $1 \mu \mathrm{M}$ melatonin relieved the suppressive effect of salt stress on the RWC content of mustard seedlings.

\section{Effects of Melatonin on ABA Content}

The endogenous ABA content was investigated over a period of 4 and 8 days to determine the influence of $1 \mu \mathrm{M}$ melatonin treatment on the recovery of salinity-stressed $(150 \mathrm{mM})$ mustard seedlings. ABA content significantly increased in the salinitystressed seedlings, compared with normal seedlings. Whereas, by observing the ABA content at day 4 and day 8 , we can see that it significantly decreased by $27 \%$ in salinity-stressed plants under $1 \mu \mathrm{M}$ melatonin treatment $(p<0.05)$. On another note, ABA content was measured in plants under normal conditions with or without melatonin treatment. By day 4 (4DAT), ABA content of normal seedlings under $1 \mu \mathrm{M}$ melatonin treatment slightly increased by $33 \%$, compared with normal seedlings under $0 \mu \mathrm{M}$ melatonin treatment (Figure 7). However, at the end of 8 days, ABA level in control plants receiving melatonin were lower than control plants without melatonin treatment. Our findings showed that $1 \mu \mathrm{M}$ melatonin treatment resulted in a reduced ABA level under $150 \mathrm{mM}$ salinity treatment.

\section{Effects of Melatonin on SA Content}

Salicylic acid content in leaves was evaluated to examine whether melatonin treatment relieved the effects of salinity stress in mustard seedlings. In salinity-treated plants, SA content in mustard leaves increased by 106 and $106 \%$ on day 4 (4DAT) and day 8 (8DAT), respectively (Figure 8). As compared with salinity treatment alone, seedlings that were treated with $1 \mu \mathrm{M}$ melatonin and $150 \mathrm{mM}$ salt had elevated SA contents by $14 \%$ (4DAT) and $12 \%$ (8DAT) $(p<0.05)$. Similarly, normal seedlings that were treated with $1 \mu \mathrm{M}$ melatonin for 8 days showed a remarkable $52 \%$ increase in SA content, compared with untreated plants (Figure 8). These values suggested that $1 \mu \mathrm{M}$ melatonin application resulted in an increased SA content in seedlings that were pretreated with or without $150 \mathrm{mM}$ salt.

\section{Effects of Melatonin on Amino Acid Content}

Seventeen amino acids were detected with different concentrations in green mustard seedlings (Figure 9). Salinity stress increased amino acid content (except for Asp) in mustard seedlings, compared with seedlings under normal conditions over 8 days. Proline (Pro) dramatically increased by $128 \%$ in salinity-stressed plants. Additionally, amino acid constituents were recovered by root application of melatonin (except for Pro) in salinity-stressed plants on day 8 (8DAT). After 8 days, glutamic acid (Glu) had the highest value, whereas the lowest value was for cystine (Cys) (28.27-1.44 ng/g) in salinity pretreated plants subjected to melatonin treatment (Figure 9). The findings indicated that $1 \mu \mathrm{M}$ melatonin application improved amino acid content under salinity-stressed $(150 \mathrm{mM})$ and normal conditions.

\section{Effects of Melatonin on Soluble Protein Content}

Protein content decreased in salinity-damaged mustard over 4 days. By day 8, protein content slightly increased by $3.29 \%$ in salinity-damaged seedlings, compared with the control $(p<0.05)$ (Figure 10). During the fourth day, the application of $1 \mu \mathrm{M}$ melatonin improved protein content by $19 \%$ in salinity-damaged plants, comparison with untreated salinitydamaged plants. However, by observing the results of protein content at day 8 , we can see that the protein content decreased by $10.8 \%$ in salinity-damaged plants under $1 \mu \mathrm{M}$ melatonin treatment (Figure 10). On another note, the protein content in control plants receiving melatonin were $6.3 \%$ higher than 

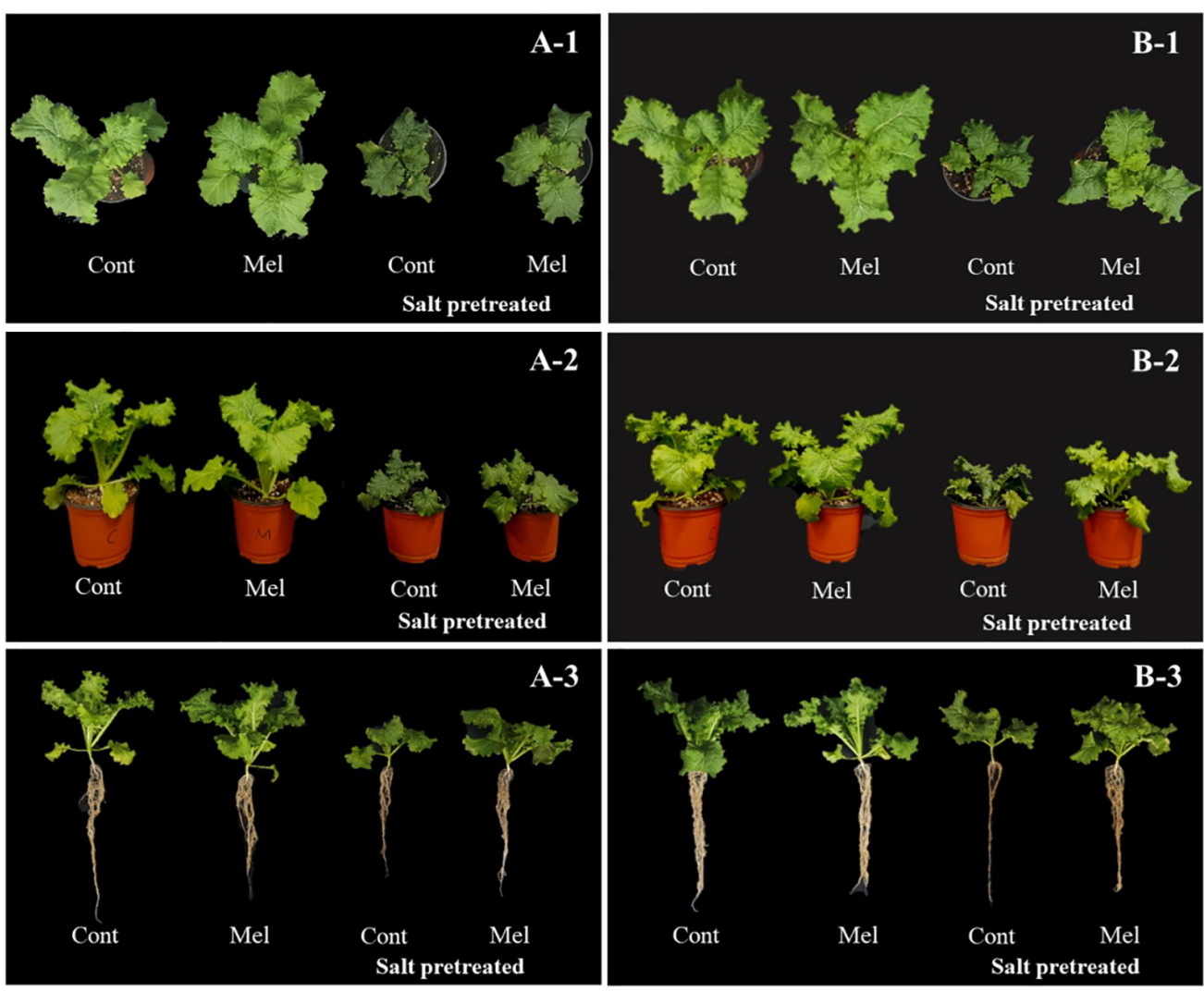

FIGURE 3 | Effect of melatonin with/without salt stress on green mustard growth during four (4DAT; A-1-3) and eight (8DAT; B-1-3) days. Treatment: control + water, control $+1 \mu \mathrm{M}$ melatonin, $150 \mathrm{mM}$ salt pre-treatment + water, $150 \mathrm{mM}$ salt pre-treatment $+1 \mu \mathrm{M}$ melatonin.

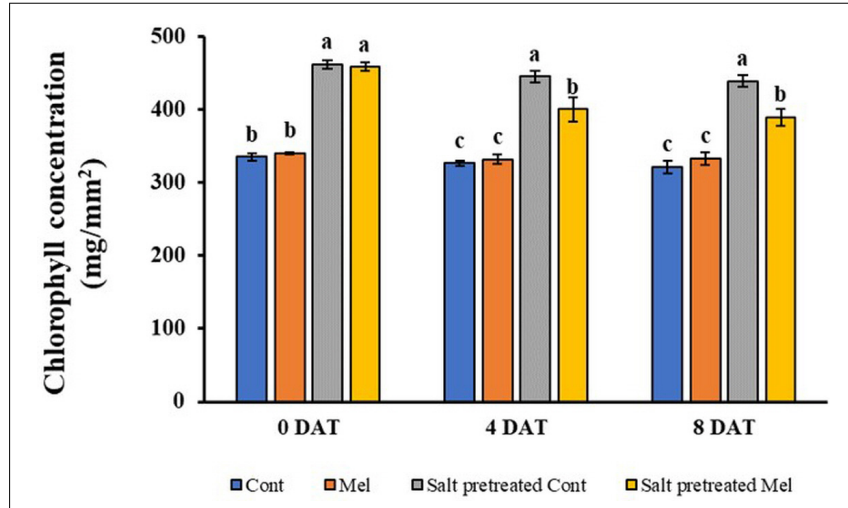

FIGURE 4 | Effect of melatonin with/without salt stress on chlorophyll content in green mustard seedlings. The results were calculated from data for 4 (4DAT) and 8 (8DAT) days. Treatment: control + water, control + $1 \mu \mathrm{M}$ melatonin, $150 \mathrm{mM}$ salt pre-treatment + water, $150 \mathrm{mM}$ salt pre-treatment $+1 \mu \mathrm{M}$ melatonin. Values show the means $\pm \operatorname{SE}(n=3)$. Letters represent significant differences at $p<0.05$ in accordance with Duncan's multiple range tests.

that in control plants without melatonin treatment. Our findings revealed that exogenous melatonin $(1 \mu \mathrm{M})$ had a positive effect on protein accumulation under control and salinity stress conditions.

\section{Effects of Melatonin on Antioxidant Activity}

Compared with seedlings treated with water alone, melatonin application led to enhancement in antioxidant activity over 8 days (except. Flavonoid). SOD, CAT, DPPH, and total phenolic contents were raised by $14,22,8$, and $12.66 \%$ in mustard seedlings under normal condition by the end of experiment (8DAT). However, flavonoid content in melatonin treated plants were $22.43 \%$ lower than untreated control plants by day 8 $(p<0.05)$. Additionally, salinity stress led to increase in SOD $(8.4 \%)$, flavonoid $(59.87 \%)$, and total phenolic $(63.65 \%)$ contents, compared with untreated plants over 8 days. Whereas, Salinity stress $(150 \mathrm{mM})$ led to a reduction in CAT $(71.5 \%)$ and DPPH (5.54\%) activity in mustard seedlings, comparison with control seedlings $(p<0.05)$. Compared with the seedlings treated with salinity alone, melatonin application contributed to additional increases in CAT and SOD activity by 51.7 and 19\%, respectively over 8 days (Figure 11). On the other hand, total phenolic and flavonoid contents reduced in salinity-stressed plants receiving $1 \mu \mathrm{M}$ melatonin treatment (Figure 11). There were no notable differences among melatonin-treated and untreated plants exposed to salinity stress.

\section{Effects of Melatonin on ROS by Use of Staining}

ROS accumulation was visualized for each treatment on day 4 (4DAT) and day 8 (8DAT) through DAB staining 

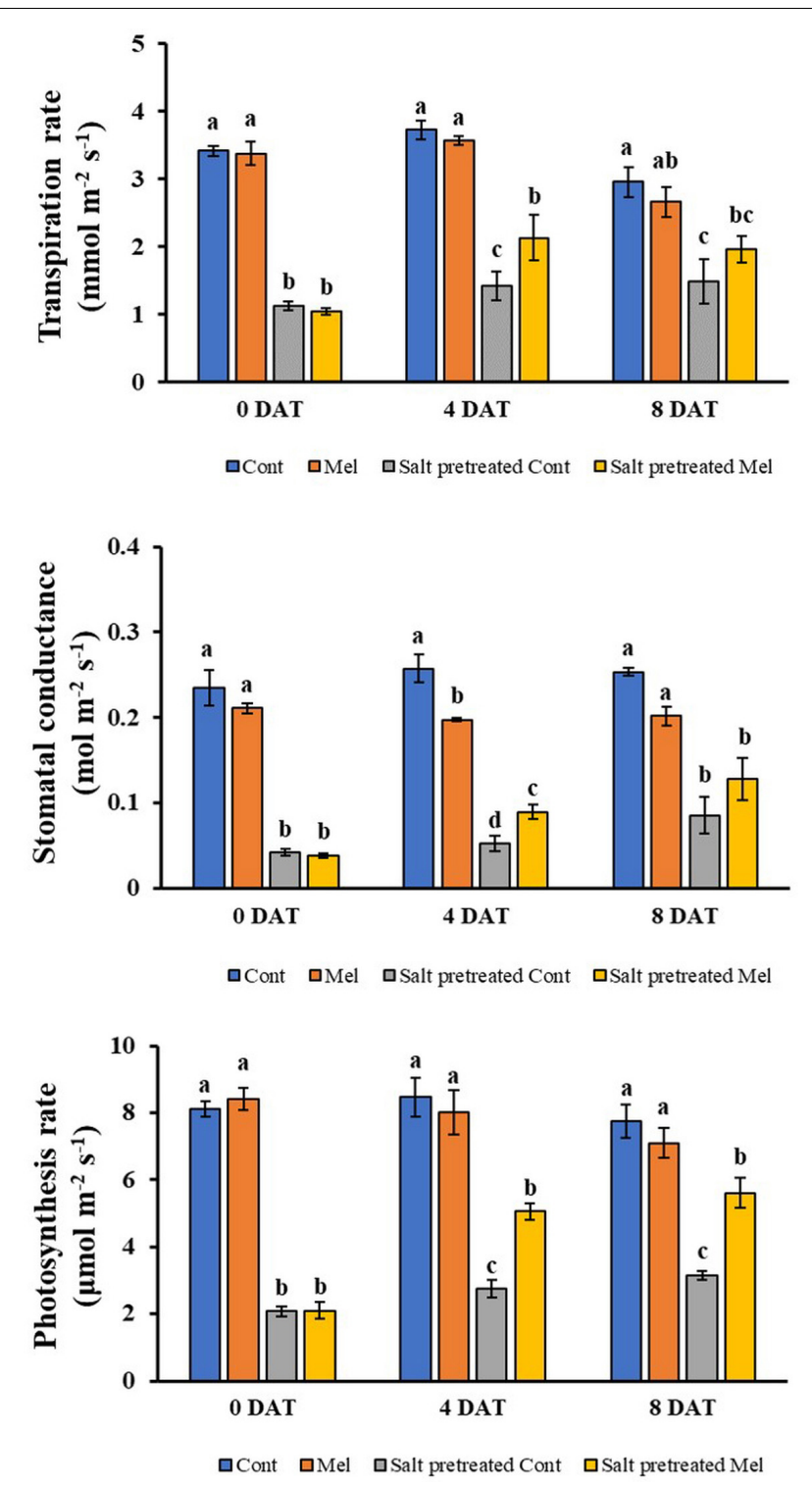

FIGURE 5 | Effect of melatonin with/without salt stress on photosynthetic parameters in green mustard seedlings. The results were calculated from data for 4 (4DAT) and 8 (8DAT) days. Treatment: control + water, control $+1 \mu \mathrm{M}$ melatonin, $150 \mathrm{mM}$ salt pre-treatment + water, $150 \mathrm{mM}$ salt pre-treatment $+1 \mu \mathrm{M}$ melatonin. Values show the means $\pm \operatorname{SE}(n=3)$. Letters represent significant differences at $p<0.05$ in accordance with Duncan's multiple range tests.

(Figures 12A-1,B-1). ROS accumulation under melatonin treatment decreased on day 4 and 8 in salinity-damaged mustard seedlings, compared with untreated damaged seedlings. The salinity-damaged plants were thoroughly stained by DAB, indicating high ROS accumulation. The intense brown color was higher in salinity-damaged plants, and this color intensity was clearly reduced in salinity-damaged plants supplemented with melatonin (Figures 12A-1,B-1). The DAB staining results unveiled high differences between treatments. The control plants treated with/without melatonin had less ROS accumulation than
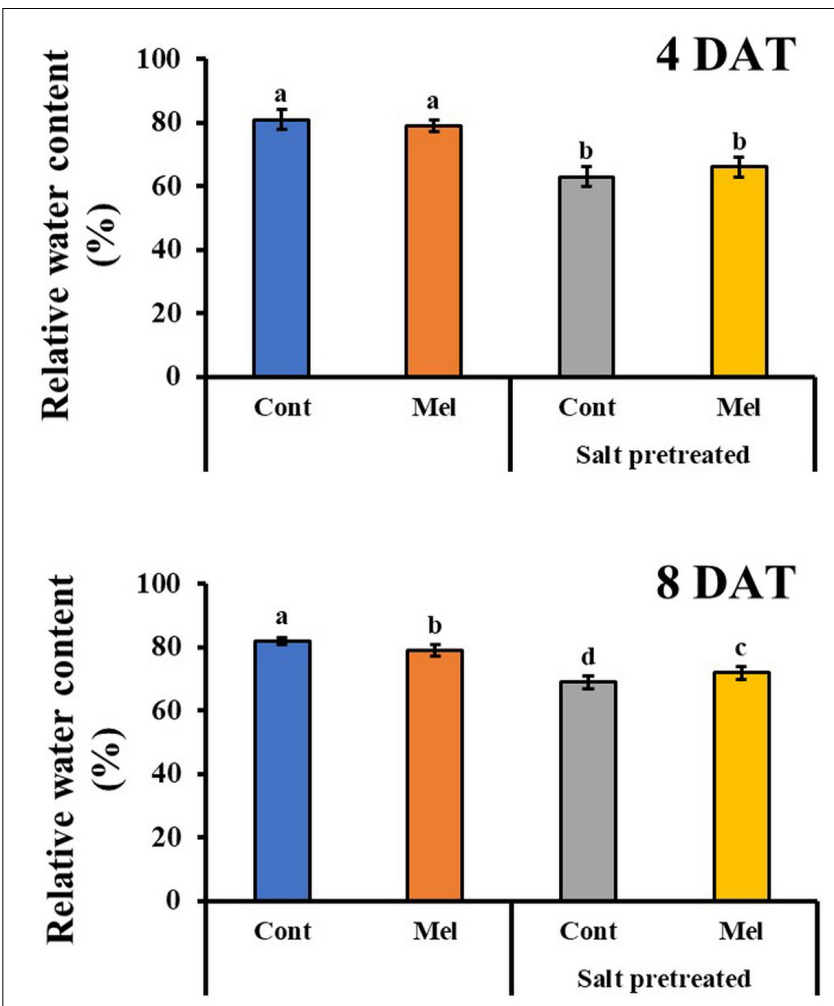

FIGURE 6 | Effect of melatonin with/without salt stress on relative water content in green mustard seedlings. The results were calculated from data for 4 (4DAT) and 8 (8DAT) days. Treatment: control + water, control + $1 \mu \mathrm{M}$ melatonin, $150 \mathrm{mM}$ salt pre-treatment + water, $150 \mathrm{mM}$ salt pre-treatment $+1 \mu \mathrm{M}$ melatonin. Values show the means $\pm \mathrm{SE}(n=3)$. Letters represent significant differences at $p<0.05$ in accordance with Duncan's multiple range tests.

salinity-damaged plants. There were no significant differences among melatonin-treated and -untreated plants under normal conditions, and we observed a similar trend for leaf color in both groups (Figures 12A-1,B-1). Our findings revealed that $1 \mu \mathrm{M}$ melatonin application led to decreased ROS accumulation in salinity-damaged plants.

\section{Effect of Melatonin on ROS Content $\left(\mathrm{H}_{2} \mathrm{O}_{2}\right)$}

The DAB staining results were confirmed by determining the $\mathrm{H}_{2} \mathrm{O}_{2}$ level in green mustard leaves subjected to different treatments. Our data agreed with the DAB staining results (Figures 12A-2,B-2). There was no noticeable difference between control plants with or without melatonin treatment. A slight decrease $(4.9 \%)$ was observed in melatonin-treated plants under normal conditions; however, salinity stress remarkably enhanced $\mathrm{H}_{2} \mathrm{O}_{2}$ level by $49.7 \%$ in green mustard leaves, compared with the control group by the end of 8 days $(p<0.05)$. Salinity-induced $\mathrm{H}_{2} \mathrm{O}_{2}$ accumulation was decreased by melatonin application. Compared with the seedlings treated with salinity alone, melatonin application contributed to $\mathrm{H}_{2} \mathrm{O}_{2}$ level reduction by $24 \%$ over 8 days. Our results indicated that $1 \mu \mathrm{M}$ melatonin application enhances the plants' recovery from salinity damage through ROS detoxification in green mustard seedlings. 

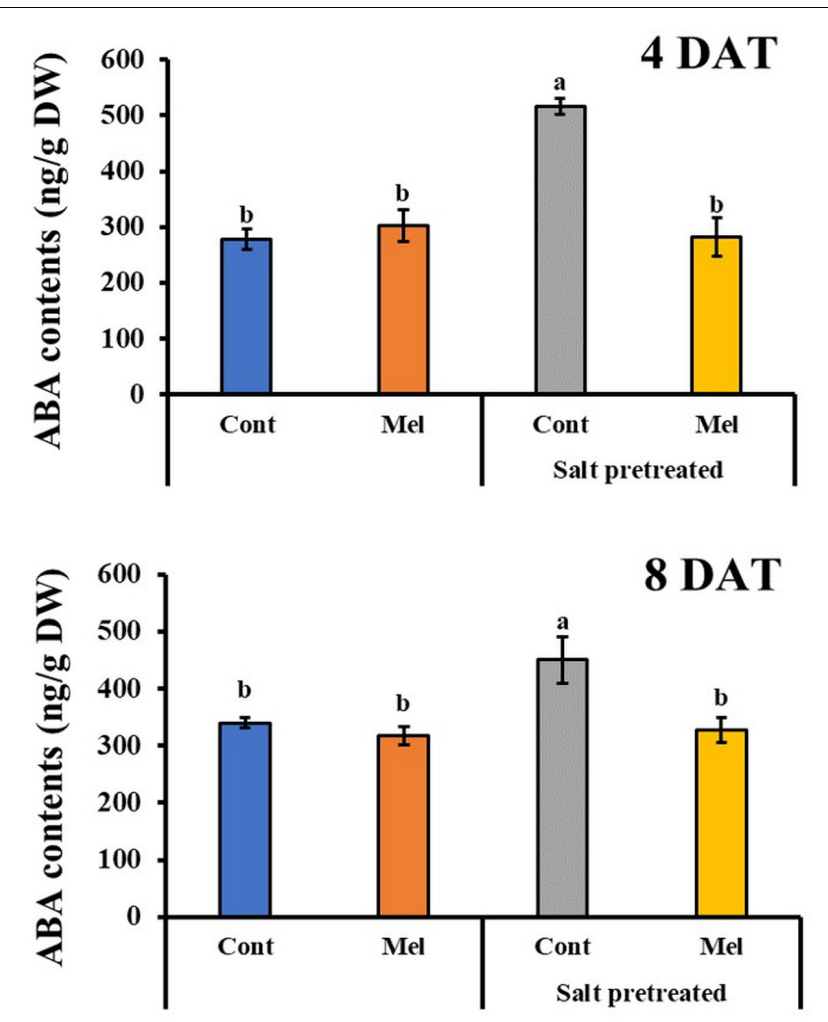

FIGURE 7 | Effect of melatonin with/without salt stress on ABA content in green mustard seedlings. The results were calculated from data for 4 (4DAT) and 8 (8DAT) days. Treatment: control + water, control + $1 \mu \mathrm{M}$ melatonin, $150 \mathrm{mM}$ salt pre-treatment + water, $150 \mathrm{mM}$ salt pre-treatment $+1 \mu \mathrm{M}$ melatonin. Values show the means $\pm \mathrm{SE}(n=3)$. Letters represent significant differences at $p<0.05$ in accordance with Duncan's multiple range tests.

\section{DISCUSSION}

Salinity is one of the major abiotic stresses that affect plant growth and productivity (Jampeetong and Brix, 2009). Salt stress interferes with all the physiologic and metabolic processes in plants, including photosynthesis and protein synthesis (Passioura, 2010). Plants have established several strategies to deal with different environmental stresses. Recently, melatonin has emerged as a research focus due to its potential in plant physiology. Melatonin is also involved in several stress responses, such as being a plant growth modulator (Wei et al., 2015). Previous studies have indicated that exogenous melatonin can alleviate salt stress in plants (Mukherjee et al., 2014). In the present study, we examined the positive impacts of exogenously applied melatonin on the recovery of salinity-damaged green mustard seedlings.

The efficiency of melatonin has been proven to be concentration-dependent, and it may present a positive or negative impact on plants. For instance, drought-stressed coffee plants showed different responses to different doses of melatonin (Campos et al., 2019). Chen et al. (2009) reported that a low melatonin concentration accelerated root growth in Brassica juncea, whereas a high melatonin concentration
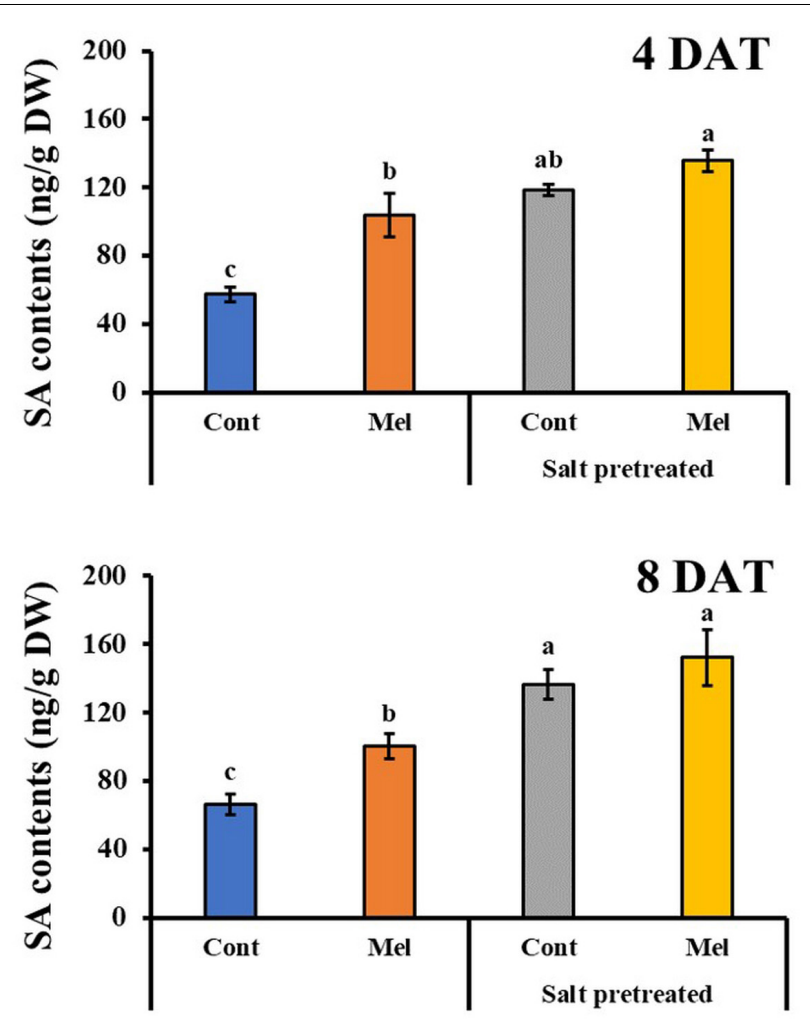

FIGURE 8 | Effect of melatonin with/without salt stress on SA content in green mustard seedlings. The results were calculated from data for 4 (4DAT) and 8 (8DAT) days. Treatment: control + water, control $+1 \mu \mathrm{M}$ melatonin, $150 \mathrm{mM}$ salt pre-treatment + water, $150 \mathrm{mM}$ salt pre-treatment $+1 \mu \mathrm{M}$ melatonin. Values show the means \pm SE $(n=3)$. Letters represent significant differences at $p<0.05$ in accordance with Duncan's multiple range tests.

suppressed it. Our findings showed that salinity-damaged seedlings supplemented with a melatonin concentration of $1 \mu \mathrm{M}$ maintained higher plant height, leaf length/width, and stem diameter in contrast to salinity-stressed plants without melatonin treatment.

Changes in chlorophyll contents caused by salt stress depends on crop. Reduction in chlorophyll contents was observed in sunflower and rice under saline condition (Tatar et al., 2010). However, chlorophyll contents increased in wheat and several species of cotton that were exposed to salinity stress (Shah et al., 2017). Similarly, we observed that chlorophyll content increased rapidly in salinity-damaged mustard seedlings. This can be attributed to the adaptive mechanisms of plants to acclimatize to salinity stress and maintain its photosynthetic functions (Acosta-Motos et al., 2017). We found that melatonin treatment resulted in decreased chlorophyll production in salinity-damaged mustard seedlings during the recovery period. Considering that salt stress activates senescence in plants, the reduced chlorophyll content may be attributed to the protective effect of melatonin against chlorophyll degradation (Arnao and Hernández-Ruiz, 2009).

Photosynthesis is one of the most important physicochemical processes that are extremely salt-sensitive 


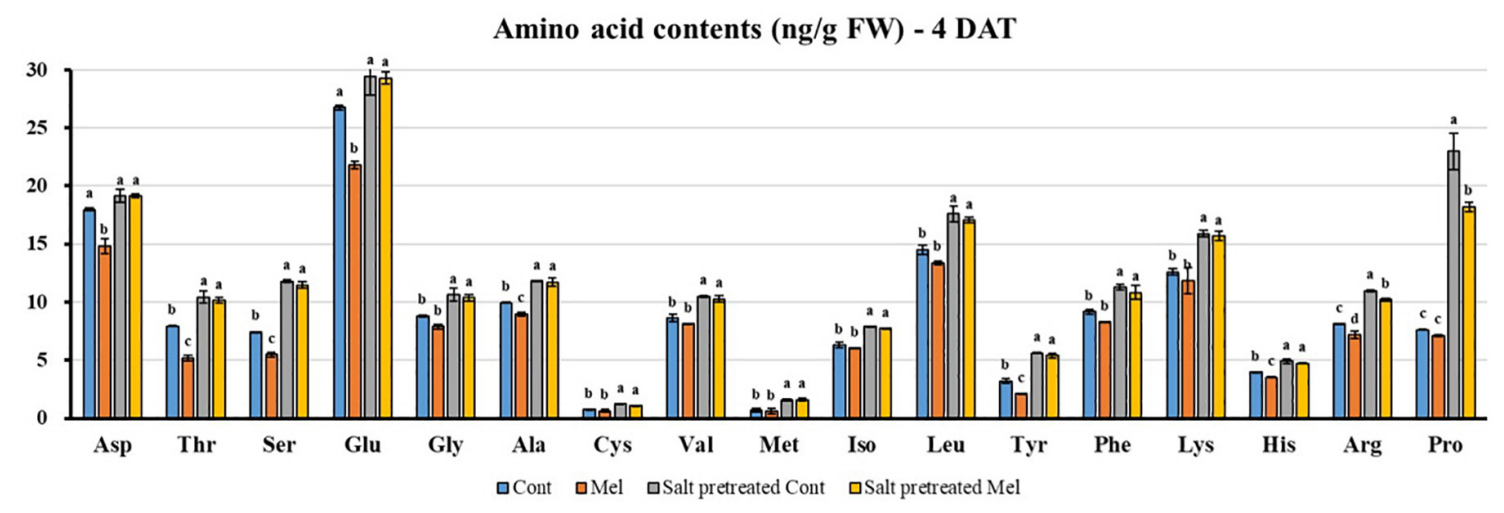

Amino acid contents (ng/g FW) - 8 DAT

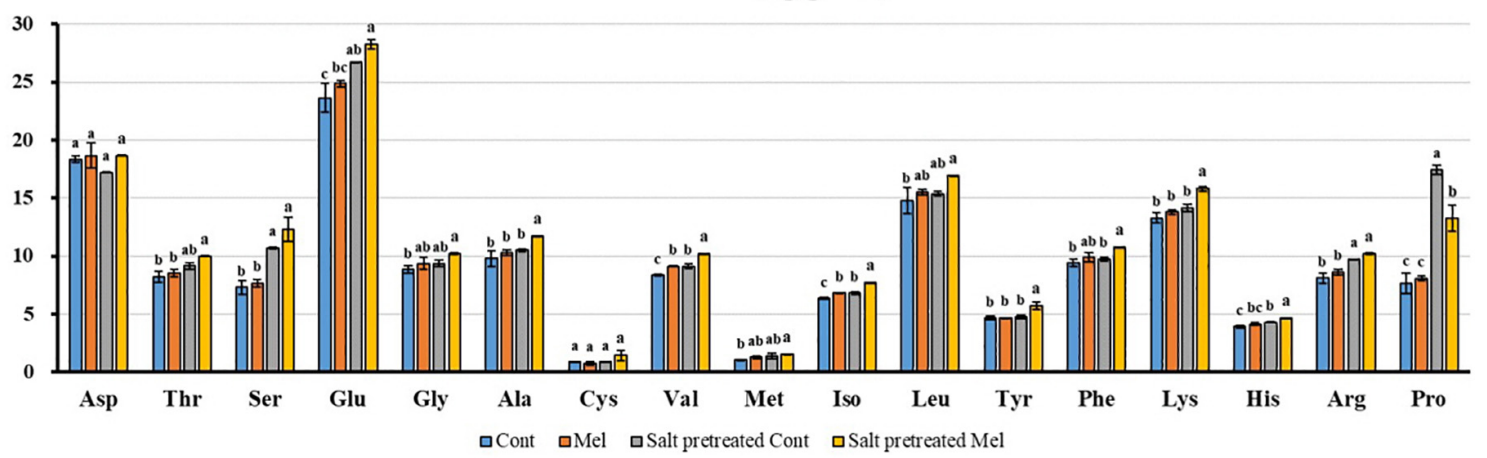

FIGURE 9 | Effect of melatonin with/without salt stress on amino acid content in green mustard seedlings. The results were calculated from data for 4 (4DAT) and 8 (8DAT) days. Treatment: control + water, control $+1 \mu \mathrm{M}$ melatonin, $150 \mathrm{mM}$ salt pre-treatment + water, $150 \mathrm{mM}$ salt pre-treatment $+1 \mu \mathrm{M}$ melatonin. Values show the means $\pm \mathrm{SE}(n=3)$. Letters represent significant differences at $p<0.05$ in accordance with Duncan's multiple range tests.

(Takahashi and Murata, 2008). Salt stress reduces stomatal opening, which leads to reduced $\mathrm{CO}_{2}$ diffusion to the mesophyll and impending changes in the photosynthetic rate. In the present study, we noticed that the photosynthetic parameters were remarkably lower in salinity-damaged plants, unquestionably because of stomatal limitations. However, exogenous melatonin application was found to improve stomatal conductance, and subsequently, the transpiration rate, photosynthetic rate, and leaf RWC were also increased in salinity-damaged seedlings during the recovery period (Hassanvand et al., 2019). Wang et al. (2016) reported that melatonin pretreatment of cucumber seedlings effectively enhanced their photosynthetic capacity under salinity stress. Similarly, melatonin pretreatment enhanced the salt tolerance of watermelon seedlings by decreasing stomatal limitation and increasing the photosynthetic rate (Li et al., 2017). Exogenous melatonin application generally contributes to a reduction in stomatal closure, and improvement in photosynthesis and water holding capacity under salinity stress.

Phytohormones not only influence the growth and development of plants, but they also effectively protect plants against biological and non-biological stresses (Hernández-Ruiz and Arnao, 2018). For instance, SA improved photosynthetic and growth parameters and antagonized oxidative damage in plants in response to abiotic stresses (Wani et al., 2017). Several studies indicated the impact of salt stress on phytohormone content, including SA and ABA (Zhang et al., 2015; Yang et al., 2017). The present study showed $\mathrm{ABA}$ and $\mathrm{SA}$ accumulation in the green mustard seedlings exposed to salinity stress. The rapid ABA and SA accumulation and the rapid reduction in stomatal size and conductance were found to be the bases for plant-induced tolerance to salt stress (Jakab et al., 2005). Furthermore, our findings showed that exogenous melatonin application can enhance the salt tolerance of green mustard by lowering its ABA content and elevating SA content, which is in accordance with recent reports (Figures 7,8 ). Several studies demonstrate that exogenously applied melatonin downregulates the genes involved in ABA biosynthesis and subsequently upregulates the genes responsible for ABA catabolism/degradation, leading to a reduced $\mathrm{ABA}$ content and enhanced plant growth under stress conditions (Sharma and Zheng, 2019; Zhan et al., 2019). Environmental stress triggers the phenylalanine ammonia-lyase enzymatic pathway, which contributes to the induction and accumulation of endogenous SA (Wani et al., 2017; PérezLlorca et al., 2019). The increased melatonin levels in plants leads to enhanced SA levels, since melatonin performs an upstream of SA synthesis and induces SA biosynthetic genes (Lee et al., 2015).

Numerous studies have indicated the impact of environmental stresses on plant proteins ( $\mathrm{Su}$ et al., 2014). To adjust 

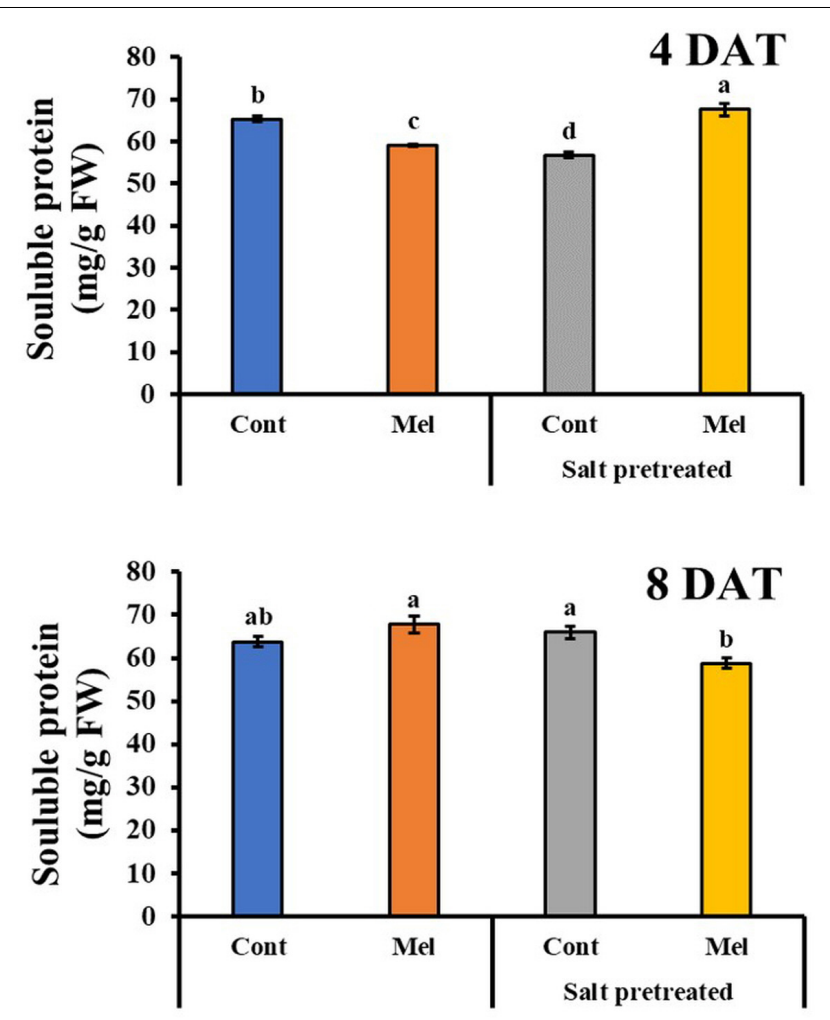

FIGURE 10 | Effect of melatonin with/without salt stress on protein content in green mustard seedlings. The results were calculated from data for 4 (4DAT) and 8 (8DAT) days. Treatment: control + water, control $+1 \mu \mathrm{M}$ melatonin, $150 \mathrm{mM}$ salt pre-treatment + water, $150 \mathrm{mM}$ salt pre-treatment $+1 \mu \mathrm{M}$ melatonin. Values show the means $\pm \operatorname{SE}(n=3)$. Letters represent significant differences at $p<0.05$ in accordance with Duncan's multiple range tests.

the osmotic pressure, plants produce proteins and other metabolites that maintain cell balance (Kishor et al., 1995). In the present study, salinity stress caused hypoxia, and the soluble protein content decreased over 4 days. However, a slight increase in protein content was observed in salinitydamaged leaves by the end of experiment. This increase can be attributed to the plants' stress response and adaptation to abiotic stresses (Chi et al., 2019). It has been observed that melatonin induced protein biosynthesis and prevents degradation; therefore, it sustains cell balance and physiologic activities (Chen et al., 2020). By the end of day 8 (8DAT), our findings showed that melatonin obviously raised the soluble protein content in green mustard seedlings under normal conditions. On day 4 (4DAT), we noticed an improvement in protein content in salinity-damaged plants with melatonin treatment, whereas, protein content clearly reduced on 8DAT in damaged seedlings treated with melatonin. This can be due to the stress-relieving effect of melatonin, which led to protein catabolism.

Plants usually produce high ROS under salt stress condition, which consequently causes oxidative damages, impaired membrane lipid functions, enzyme inactivation, and impeded metabolic activities (Huang et al., 2019). In the present study, we observed that $\mathrm{H}_{2} \mathrm{O}_{2}$ level were remarkably high in salinity-damaged plants, which agrees with previous reports. Exogenous melatonin application obviously mitigated the high $\mathrm{H}_{2} \mathrm{O}_{2}$ level in salinity-damaged plants by the end of 8 days (Figure 12B-2). This indicated that exogenously applied melatonin may efficiently protect cell membranes under salinity stress from oxidative damages. Owing to its solubility in either water or lipid, melatonin can easily cross the aqueous cytoplasm and lipid membranes, and prevent oxidative damages by deactivating and scavenging toxic substances (Venegas et al., 2012).

Plants have developed defensive mechanisms that consist of antioxidants with enzymatic or non-enzymatic activity to cope with oxidative damage and reduce excessive ROS accumulation. Several studies have demonstrated that melatonin upsurges the activity of enzymatic antioxidants under stressful conditions (Ahmad et al., 2019; Sharma and Zheng, 2019). Consistently, our results confirmed these previous works. Melatonin increased SOD, CAT, and DPPH activities in both unstressed and stressed seedlings. In the present study, the activity of CAT and DPPH reduced in the salinity-damaged plants, whereas flavonoid, SOD, and total phenolic content increased in the salinity-damaged plants, compared with the control plants. This shows the capability of antioxidants to rapidly react toward environmental stresses. Depending on the concentration of salt, SOD activity may increase, leading to scavenging excessive ROS and reducing oxidative damages (Song et al., 2006). Overall, our findings showed that the crosstalk among melatonin and antioxidants contribute to defer senescence in plants.

Amino acids directly or indirectly regulate plant responses to environmental stresses (Ashraf and Harris, 2004). In our experiment, salinity stress increased the amino acid contents (Glu, Ser, Thr, Arg, and Pro) in green mustard seedlings. This accumulation suggests that they have a role in osmotic adaptation apart from their roles in metabolism (Azevedo Neto et al., 2009). Several reviews have reported increased amino acid contents under salt stress (Rare, 1990; Mansour, 2000). Moreover, root application of melatonin rescued amino acid content in most cases (except for Pro) in salinity-damaged seedlings during the recovery period. The highest and lowest peaks belong to glutamic acid (Glu) and cysteine (Cys), respectively, in salinitydamaged plants with or without melatonin supplementation. Glu functions in nitrogen metabolism and is commonly used as a substrate for amino acid synthesis (Vance and Zaerr, 1990). Moreover, it plays a role in proline synthesis in response to abiotic stresses (Planchet and Limami, 2015). ElShintinawy and El-Shourbagy (2001) found that the changes in Glu levels are correlated with Cys metabolism in plants under salt stress condition. These two amino acids act as a precursor of glutathione, a molecule that plays a crucial role in preventing ROS accumulation (Noctor and Foyer, 1998). Our results showed that root application of melatonin rescued Glu and Cys contents in salinity-damaged green mustard seedlings during the recovery period. This confirms the influence of melatonin on the metabolic pathways of these amino acids. 

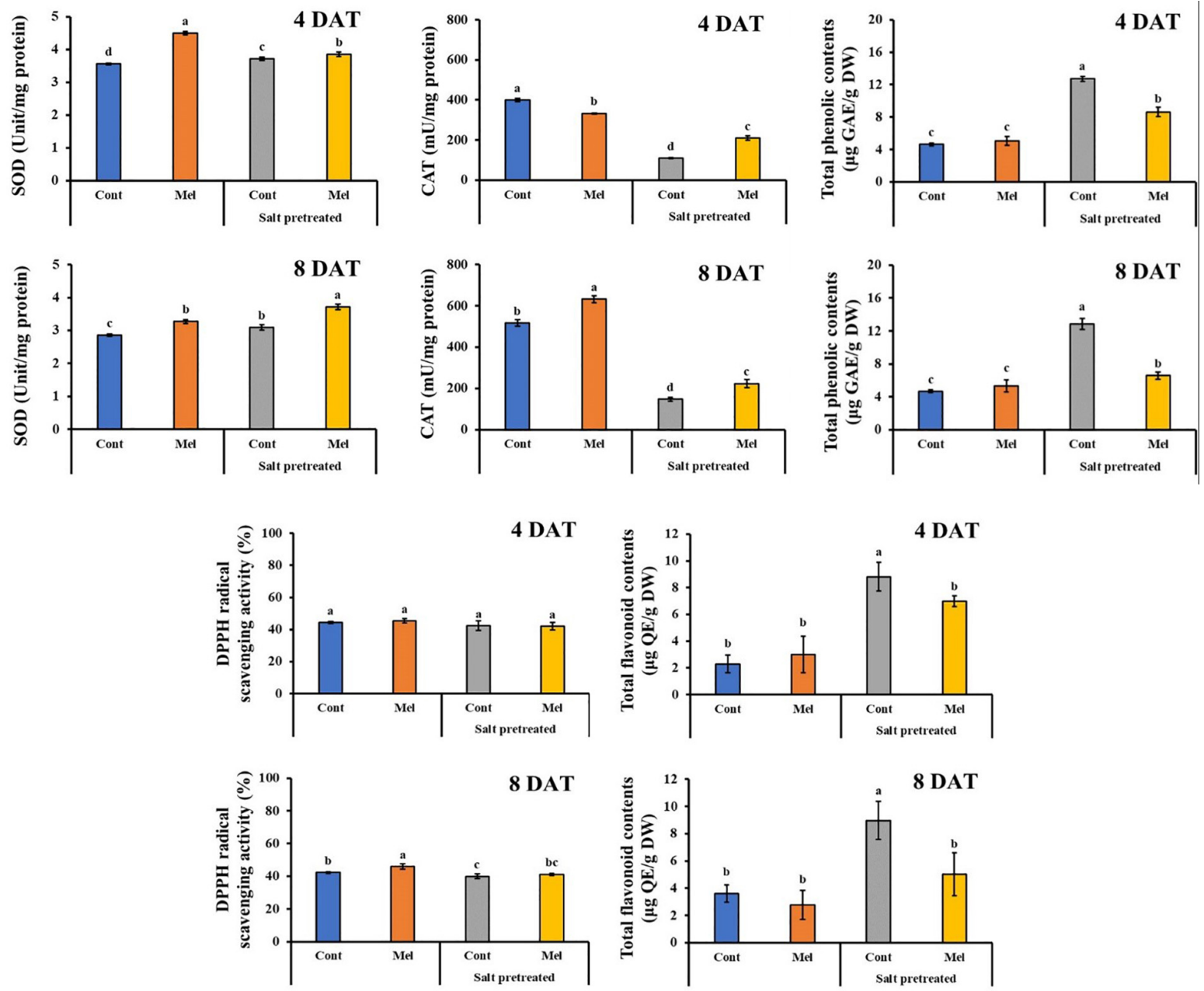

FIGURE 11 | Effect of melatonin with/without salt stress on antioxidant content in green mustard seedlings. The results were calculated from data for 4 (4DAT) and 8 (8DAT) days. Treatment: control + water, control + $1 \mu \mathrm{M}$ melatonin, $150 \mathrm{mM}$ salt pre-treatment + water, $150 \mathrm{mM}$ salt pre-treatment + $1 \mu \mathrm{M}$ melatonin. Values show the means $\pm \mathrm{SE}(n=3)$. Letters represent significant differences at $p<0.05$ in accordance with Duncan's multiple range tests.

The Arg accumulation in green mustard subjected to salinity stress agrees previous works (Santa-Cruz et al., 1999). Rabe and Lovatt (1984) indicated that the increased Arg content in stressed plants can be due to de novo synthesis, because it is used for ammonia detoxification during reduced growth. The findings from this study showed that exogenous melatonin application led to an increased Arg content in salinity-damaged seedlings. Fan et al. (2015) showed the comprehensive influence of melatonin on several metabolic pathways (amino acids, organic acids, and carbohydrates) involved in plant resistance toward cold stress.

Leucine content decreased in salinity-damaged plants by day 8. El-Shintinawy and El-Shourbagy (2001) hypothesized that the reduction in leucine content may be due to the suppression of acetolactate synthase activity under salt stress. Additionally, previous reports demonstrated that changes in Leu content have also been correlated with protein catabolism/metabolism (Raggi, 1994); therefore, a decreased Leu content implies protein synthesis improvement. The findings from the present study showed that Leu accumulated in salinity-damaged green mustard under melatonin treatment (Figure 9). Shi et al. (2015a) reported Leu enhancement in melatonin-pretreated Bermuda grass under salt stress.

Several studies have been conducted on Asp accumulation in several plants species exposed to salt stress. They suggested that this accumulation can be used in salt-tolerant mechanisms and biosynthesis of the other amino acids (Azevedo Neto et al., 2009; Farhangi-Abriz and Ghassemi-Golezani, 2016). Our findings follow the same trend, as the Asp content increased in salinity-damaged seedlings for 4 days. After 8 days, the Asp content reduced in salinity-damaged seedlings, which may be due to the rapid Asp metabolism into the other products (Queiroz et al., 2012). Asp accumulation in salinity-damaged green mustard seedlings occurred after melatonin application. Melatonin-pretreated plant, Cynodon dactylon, enhanced Asp content under salt stress (Shi et al., 


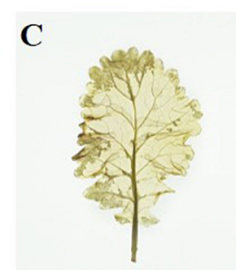

S.C

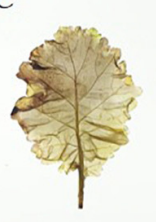

C

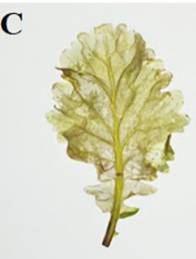

S.C

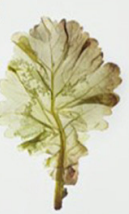

M

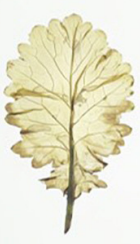

S.M

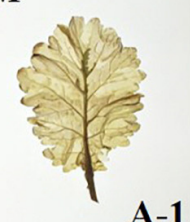

A-1

$\mathbf{M}$

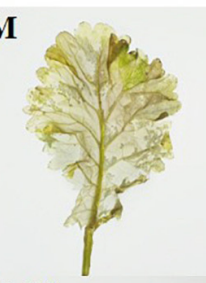

S.M

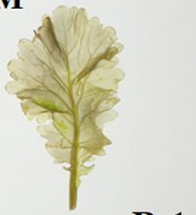

B-1

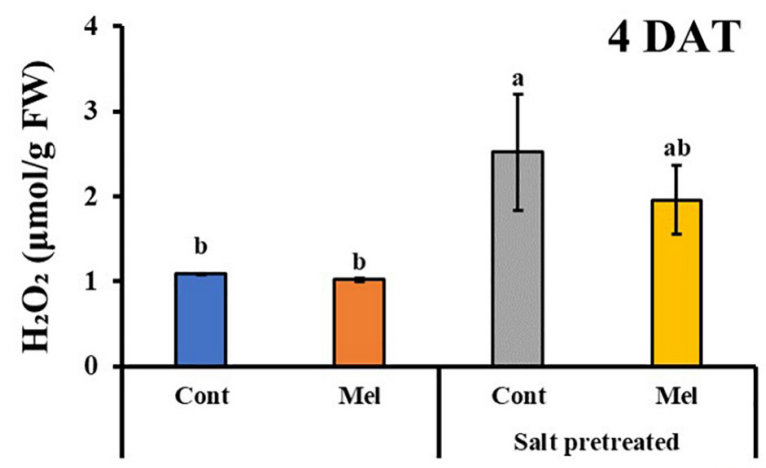

A-2

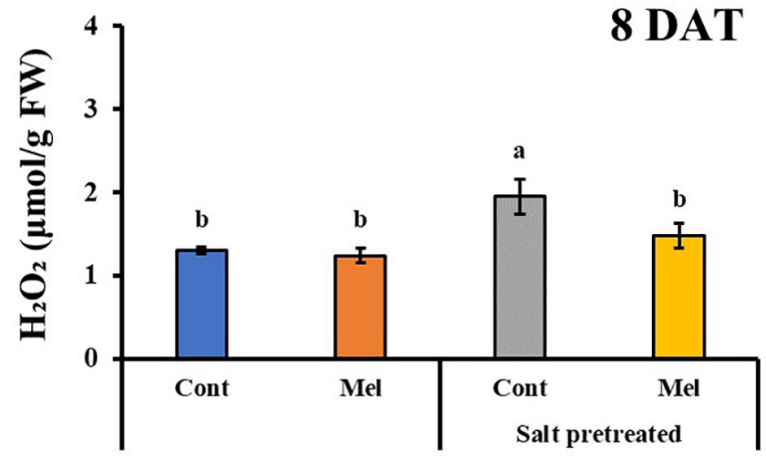

B-2

FIGURE 12 | Effect of melatonin with/without salt stress on $\mathrm{H}_{2} \mathrm{O}_{2}$ content in green mustard seedlings. DAB staining was used to visualize the accumulation of $\mathrm{H}_{2} \mathrm{O}_{2}$ in leaves on day 4 (4DAT; $\mathbf{A - 1}$ ) and day 8 (8DAT; B-1) of treatment. The $\mathrm{H}_{2} \mathrm{O}_{2}$ contents were calculated from data for 4 (4DAT; A-2) and 8 (8DAT; B-2) days. Treatment: control + water, control $+1 \mu \mathrm{M}$ melatonin, $150 \mathrm{mM}$ salt pre-treatment + water, $150 \mathrm{mM}$ salt pre-treatment $+1 \mu \mathrm{M}$ melatonin. Values represent the means $\pm \mathrm{SE}(n=3)$. Letters represent significant differences at $p<0.05$ in accordance with Duncan's multiple range tests.

2015a). This demonstrates the effect of melatonin on amino acid metabolism.

A rapid increase was observed in the proline content in salinity-damaged green mustard, which is in agreement with the findings of previous studies on several plant species (Khattab, 2007; Bassuony et al., 2008). Accumulation of solutes called osmoprotectants, such as proline, may be a plant's strategy to endure abiotic stresses (Dawood and El-Awadi, 2015; Liu et al., 2018). The increased proline content has been associated with enhanced plant performance under environmental stresses (Nanjo et al., 1999). Furthermore, proline may play a role as a reservoir of organic nitrogen that can be consumed during the recovery period to help plants withstand environmental stresses, such as salinity and drought (Rare, 1990; Sairam and Tyagi, 2004). In the present study, root application of melatonin led to a decreased proline content in salinitydamaged seedlings. Earlier studies indicated improvement in proline content in plants supplemented with a suitable concentration of melatonin under abiotic stresses (Liu et al., 2018; Ahmad et al., 2019). The observed decrease in proline content may be attributed to proline decomposition due to the stress-relieving effect of melatonin. Similarly, Zamani et al. (2019) reported that exogenous melatonin treatment reduced proline content in fenugreek (Trigonella foenum-gracum L.) under drought stress. As described previously, proline degradation is triggered in darkness and during stress relief, and is catalyzed by $\mathrm{PDH}$ (proline dehydrogenase) and $\mathrm{P} 5 \mathrm{CDH}$ ( $\Delta$ '-pyrroline-5-carboxylate dehydrogenase). Considering the alleviating impact of melatonin on oxidative damage caused by salt stress, proline degradation may be triggered during stress relief (Antoniou et al., 2017; Zamani et al., 2019). Additionally, proline degradation is needed to maintain growth and development under salt stress.

In a nutshell, our results confirmed that almost 5-week-old (38-day-old) salinity-damaged green mustard seedlings were recovered significantly by exogenous melatonin application. Our approach unraveled that exogenous melatonin can effectively improve performance and yield of mustard seedlings under either unstressed or stressed (salinity) conditions in an eco-friendly manner for a more sustainable agriculture. Future studies are needed to throw light on the genetic mechanisms and metabolic pathways during the recovery period in salinity-damaged green mustard plants under melatonin treatment. 


\section{DATA AVAILABILITY STATEMENT}

The original contributions presented in the study are included in the article/supplementary material, further inquiries can be directed to the corresponding author/s.

\section{AUTHOR CONTRIBUTIONS}

H-SP and S-MK planned for research and analyzed the data. $\mathrm{H}-\mathrm{SP}$ conducted the experiment. EK analyzed the data and wrote the manuscript. I-JL supervised the experiment and provided the resources. AA-S edited the manuscript. All the authors approved the manuscript.

\section{REFERENCES}

Acosta-Motos, J. R., Ortuño, M. F., Bernal-Vicente, A., Diaz-Vivancos, P., SanchezBlanco, M. J., and Hernandez, J. A. (2017). Plant responses to salt stress: adaptive mechanisms. Agronomy 7:18. doi: 10.3390/agronomy7010018

Adhikari, B., Dhungana, S. K., Ali, M. W., Adhikari, A., Kim, I.-D., and Shin, D.H. (2018). Resveratrol, total phenolic and flavonoid contents, and antioxidant potential of seeds and sprouts of Korean peanuts. Food Sci. Biotechnol. 27, 1275-1284. doi: 10.1007/s10068-018-0364-7

Ahmad, S., Kamran, M., Ding, R., Meng, X., Wang, H., Ahmad, I., et al. (2019). Exogenous melatonin confers drought stress by promoting plant growth, photosynthetic capacity and antioxidant defense system of maize seedlings. PeerJ 7:e7793. doi: 10.7717/peerj.7793

Antoniou, C., Chatzimichail, G., Xenofontos, R., Pavlou, J. J., Panagiotou, E., Christou, A., et al. (2017). Melatonin systemically ameliorates drought stress-induced damage in $M$ edicago sativa plants by modulating nitro-oxidative homeostasis and proline metabolism. J. Pineal Res. 62:e12401. doi: $10.1111 /$ jpi.12401

Arnao, M. B., and Hernández-Ruiz, J. (2014). Melatonin: plant growth regulator and/or biostimulator during stress? Trends Plant Sci. 19, 789-797. doi: 10.1016/ j.tplants.2014.07.006

Arnao, M. B., and Hernández-Ruiz, J. (2009). Protective effect of melatonin against chlorophyll degradation during the senescence of barley leaves. J. Pineal Res. 46, 58-63. doi: 10.1111/j.1600-079x.2008.00625.x

Arnao, M. B., and Hernández-Ruiz, J. (2015). Functions of melatonin in plants: a review. J. Pineal Res. 59, 133-150. doi: 10.1111/jpi.12253

Ashraf, M., and Harris, P. J. C. (2004). Potential biochemical indicators of salinity tolerance in plants. Plant Sci. 166, 3-16. doi: 10.1016/j.plantsci.2003.10.024

Ashraf, M., and Iram, A. (2005). Drought stress induced changes in some organic substances in nodules and other plant parts of two potential legumes differing in salt tolerance. Flora Morphol. Distrib. Funct. Ecol. Plants 200, 535-546. doi: 10.1016/j.flora.2005.06.005

Azevedo Neto, A. D., Prisco, J. T., and Gomes-Filho, E. (2009). Changes in soluble amino-N, soluble proteins and free amino acids in leaves and roots of salt-stressed maize genotypes. J. Plant Interact. 4, 137-144. doi: 10.1080/ 17429140902866954

Bassuony, F., Hassanein, R., Baraka, D., and Khalil, R. (2008). Physiological effects of nicotinamide and ascorbic acid on Zea mays plant grown under salinity stress II-Changes in nitrogen constituent, protein profiles, protease enzyme and certain inorganic cations. Austr. J. Basic Appl. Sci. 2, 350-359.

Bradford, M. M. (1976). A rapid and sensitive method for the quantitation of microgram quantities of protein utilizing the principle of protein-dye binding. Anal. Biochem. 72, 248-254. doi: 10.1016/0003-2697(76)90527-3

Campos, C. N., Ávila, R. G., de Souza, K. R. D., Azevedo, L. M., and Alves, J. D. (2019). Melatonin reduces oxidative stress and promotes drought tolerance in young Coffea arabica L. plants. Agric. Water Manag. 211, 37-47. doi: 10.1016/j. agwat.2018.09.025

\section{FUNDING}

This study was supported by the Agenda Program (Project No. PJ015163032020) Rural Development Administration, South Korea.

\section{ACKNOWLEDGMENTS}

We would like to acknowledge a deep gratitude to the Kyungpook National University, Department of School of Applied Biosciences, for providing us a well-equipped platform to undergo our research activities.

Carrillo-Vico, A., Lardone, P. J., Álvarez-Sánchez, N., Rodríguez-Rodríguez, A., and Guerrero, J. M. (2013). Melatonin: buffering the immune system. Int. J. Mol. Sci. 14, 8638-8683. doi: 10.3390/ijms14048638

Chen, L., Liu, L., Lu, B., Ma, T., Jiang, D., Li, J., et al. (2020). Exogenous melatonin promotes seed germination and osmotic regulation under salt stress in cotton (Gossypium hirsutum L.). PLoS One 15:e0228241. doi: 10.1371/journal.pone. 0228241

Chen, M., Yang, Z., Liu, J., Zhu, T., Wei, X., Fan, H., et al. (2018). Adaptation mechanism of salt excluders under saline conditions and its applications. Int. J. Mol. Sci. 19:3668. doi: 10.3390/ijms19113668

Chen, Q., Qi, W.-B., Reiter, R. J., Wei, W., and Wang, B.-M. (2009). Exogenously applied melatonin stimulates root growth and raises endogenous indoleacetic acid in roots of etiolated seedlings of Brassica juncea. J. Plant Physiol. 166, 324-328. doi: 10.1016/j.jplph.2008.06.002

Chi, Y. H., Koo, S. S., Oh, H. T., Lee, E. S., Park, J. H., Phan, K. A. T., et al. (2019) The physiological functions of universal stress proteins and their molecular mechanism to protect plants from environmental stresses. Front. Plant Sci. 10:750. doi: 10.3389/fpls.2019.00750

Chowdhury, I., Sengupta, A., and Maitra, S. K. (2008). Melatonin: fifty years of scientific journey from the discovery in bovine pineal gland to delineation of functions in human. Indian J. Biochem. Biophys. 45, 289-304.

Dawood, M. G., and El-Awadi, M. E. (2015). Alleviation of salinity stress on Vicia faba L. plants via seed priming with melatonin. Acta Biol. Colomb. 20, 223-235.

Deinlein, U., Stephan, A. B., Horie, T., Luo, W., Xu, G., and Schroeder, J. I. (2014). Plant salt-tolerance mechanisms. Trends Plant Sci. 19, 371-379. doi: 10.1016/j.tplants.2014.02.001

Dubbels, R., Reiter, R. J., Klenke, E., Goebel, A., Schnakenberg, E., Ehlers, C., et al. (1995). Melatonin in edible plants identified by radioimmunoassay and by high performance liquid chromatography-mass spectrometry. J. Pineal Res. 18, 28-31. doi: 10.1111/j.1600-079x.1995.tb00136.x

El-Shintinawy, F., and El-Shourbagy, M. (2001). Alleviation of changes in protein metabolism in NaCl-stressed wheat seedlings by thiamine. Biol. Plant. 44, 541-545. doi: 10.1023/a:1013738603020

Enyedi, A. J., Yalpani, N., Silverman, P., and Raskin, I. (1992). Localization, conjugation, and function of salicylic acid in tobacco during the hypersensitive reaction to tobacco mosaic virus. Proc. Natl. Acad. Sci. U.S.A. 89, 2480-2484. doi: $10.1073 /$ pnas.89.6.2480

Fan, J., Hu, Z., Xie, Y., Chan, Z., Chen, K., Amombo, E., et al. (2015). Alleviation of cold damage to photosystem II and metabolisms by melatonin in Bermudagrass. Front. Plant Sci. 6:925. doi: 10.3389/fpls.2015.00925

Farhangi-Abriz, S., and Ghassemi-Golezani, K. (2016). Improving amino acid composition of soybean under salt stress by salicylic acid and jasmonic acid. J. Appl. Bot. Food Qual. 89, 243-248.

Hassanvand, F., Nejad, A. R., and Fanourakis, D. J. I. C. (2019). Morphological and physiological components mediating the silicon-induced enhancement of geranium essential oil yield under saline conditions. Ind. Crops Prod. 134, 19-25. doi: 10.1016/j.indcrop.2019.03.049 
Hernández-Ruiz, J., and Arnao, M. B. (2018). Relationship of melatonin and salicylic acid in biotic/abiotic plant stress responses. Agronomy 8:33. doi: 10 . 3390/agronomy 8040033

Huang, B., Chen, Y.-E., Zhao, Y.-Q., Ding, C.-B., Liao, J.-Q., Hu, C., et al. (2019). Exogenous melatonin alleviates oxidative damages and protects photosystem II in Maize seedlings under drought stress. Front. Plant Sci. 10:677. doi: 10.3389/ fpls.2019.00677

Jakab, G., Ton, J., Flors, V., Zimmerli, L., Métraux, J.-P., and Mauch-Mani, B. (2005). Enhancing Arabidopsis salt and drought stress tolerance by chemical priming for its abscisic acid responses. Plant Physiol. 139, 267-274. doi: 10.1104/ pp. 105.065698

Jampeetong, A., and Brix, H. (2009). Effects of $\mathrm{NaCl}$ salinity on growth, morphology, photosynthesis and proline accumulation of Salvinia natans. Aquat. Bot. 91, 181-186. doi: 10.1016/j.aquabot.2009.05.003

Jana, S., and Choudhuri, M. A. (1982). Glycolate metabolism of three submersed aquatic angiosperms during ageing. Aquat. Bot. 12, 345-354. doi: 10.1016/03043770(82)90026- 2

Jo, S.-H., Cho, C.-Y., Ha, K.-S., Lee, J.-Y., Choi, H.-Y., Kwon, Y.-I., et al. (2018). In vitro and in vivo anti-hyperglycemic effects of green and red mustard leaves (Brassica juncea var. integrifolia). J. Food Biochem. 42:e12583. doi: 10.1111/jfbc. 12583

Ke, Q., Wang, Z., Ji, C. Y., Jeong, J. C., Lee, H.-S., Li, H., et al. (2016). Transgenic poplar expressing codA exhibits enhanced growth and abiotic stress tolerance. Plant Physiol. Biochem. 100, 75-84. doi: 10.1016/j.plaphy.2016.01.004

Ke, Q., Ye, J., Wang, B., Ren, J., Yin, L., Deng, X., et al. (2018). Melatonin mitigates salt stress in wheat seedlings by modulating polyamine metabolism. Front. Plant Sci. 9:914. doi: 10.3389/fpls.2018.00914

Khattab, H. (2007). Role of glutathione and polyadenylic acid on the oxidative defense systems of two different cultivars of canola seedlings grown under saline conditions. Austr. J. Basic Appl. Sci. 1, 323-334.

Kim, Y.-H., Khan, A. L., Kim, D.-H., Lee, S.-Y., Kim, K.-M., Waqas, M., et al. (2014). Silicon mitigates heavy metal stress by regulating P-type heavy metal ATPases, Oryza sativa low silicon genes, and endogenous phytohormones. BMC Plant Biol. 14:13. doi: 10.1186/1471-2229-14-13

Kishor, P. K., Hong, Z., Miao, G.-H., Hu, C.-A. A., and Verma, D. P. S. (1995). Overexpression of [delta]-pyrroline-5-carboxylate synthetase increases proline production and confers osmotolerance in transgenic plants. Plant Physiol. 108, 1387-1394. doi: 10.1104/pp.108.4.1387

Lee, H. Y., Byeon, Y., Tan, D. X., Reiter, R. J., and Back, K. (2015). Arabidopsis serotonin $\mathrm{N}$-acetyltransferase knockout mutant plants exhibit decreased melatonin and salicylic acid levels resulting in susceptibility to an avirulent pathogen. J. Pineal Res. 58, 291-299. doi: 10.1111/jpi.12214

Lee, S.-H., Lillehoj, H. S., Chun, H.-K., Tuo, W., Park, H.-J., Cho, S.-M., et al. (2007). In vitro treatment of chicken peripheral blood lymphocytes, macrophages, and tumor cells with extracts of Korean medicinal plants. Nutr. Res. 27, 362-366. doi: 10.1016/j.nutres.2007.04.001

Li, C., Tan, D. X., Liang, D., Chang, C., Jia, D., and Ma, F. (2015). Melatonin mediates the regulation of ABA metabolism, free-radical scavenging, and stomatal behaviour in two Malus species under drought stress. J. Exp. Bot. 66, 669-680. doi: 10.1093/jxb/eru476

Li, C., Wang, P., Wei, Z., Liang, D., Liu, C., Yin, L., et al. (2012). The mitigation effects of exogenous melatonin on salinity-induced stress in Malus hupehensis. J. Pineal Res. 53, 298-306. doi: 10.1111/j.1600-079X.2012.00999.x

Li, H., Chang, J., Chen, H., Wang, Z., Gu, X., Wei, C., et al. (2017). Exogenous melatonin confers salt stress tolerance to watermelon by improving photosynthesis and redox homeostasis. Front. Plant Sci. 8:295. doi: 10.3389/fpls. 2017.00295

Liu, Z., Cai, J.-S., Li, J.-J., Lu, G.-Y., Li, C.-S., Fu, G.-P., et al. (2018). Exogenous application of a low concentration of melatonin enhances salt tolerance in rapeseed (Brassica napus L.) seedlings. J. Integrat. Agric. 17, 328-335. doi: 10.1016/s2095-3119(17)61757-x

Mansour, M. M. F. (2000). Nitrogen containing compounds and adaptation of plants to salinity stress. Biol. Plant. 43, 491-500. doi: 10.1023/A:1002873531707

Mishra, S., Singh, B. R., Naqvi, A. H., and Singh, H. B. (2017). Potential of biosynthesized silver nanoparticles using Stenotrophomonas sp. BHU-S7 (MTCC 5978) for management of soil-borne and foliar phytopathogens. Sci. Rep. 7, 45154-45154. doi: 10.1038/srep45154
Mukherjee, S., David, A., Yadav, S., Baluska, F., and Bhatla, S. C. (2014). Salt stressinduced seedling growth inhibition coincides with differential distribution of serotonin and melatonin in sunflower seedling roots and cotyledons. Physiol. Plant 152, 714-728. doi: 10.1111/ppl.12218

Nanjo, T., Kobayashi, M., Yoshiba, Y., Sanada, Y., Wada, K., Tsukaya, H., et al. (1999). Biological functions of proline in morphogenesis and osmotolerance revealed in antisense transgenic Arabidopsis thaliana. Plant J. 18, 185-193. doi: 10.1046/j.1365-313x.1999.00438.x

Nawaz, M. A., Huang, Y., Bie, Z., Ahmed, W., Reiter, R. J., Niu, M., et al. (2016). Melatonin: current status and future perspectives in plant science. Front. Plant Sci. 6:1230. doi: 10.3389/fpls.2015.01230

Noctor, G., and Foyer, C. H. (1998). Ascorbate and glutathione: keeping active oxygen under control. Annu. Rev. Plant Biol. 49, 249-279. doi: 10.1146/ annurev.arplant.49.1.249

Passioura, J. B. (2010). Scaling up: the essence of effective agricultural research. Funct. Plant Biol. 37, 585-591. doi: 10.1071/fp10106

Pérez-Llorca, M., Muñoz, P., Müller, M., and Munné-Bosch, S. (2019). Biosynthesis, metabolism and function of auxin, salicylic acid and melatonin in climacteric and non-climacteric fruits. Front. Plant Sci. 10:136. doi: 10.3389/ fpls.2019.00136

Planchet, E., and Limami, A. M. (2015). "Amino acid synthesis under abiotic stress," in Amino Acids in Higher Plants, ed. J. P. F. D’Mello (Oxfordshire: CABI Publishers).

Qi, Q., Rose, P. A., Abrams, G. D., Taylor, D. C., Abrams, S. R., and Cutler, A. J. (1998). (+)-Abscisic acid metabolism, 3-ketoacyl-coenzyme A synthase gene expression, and very-long-chain monounsaturated fatty acid biosynthesis in Brassica napus embryos. Plant Physiol. 117, 979-987. doi: 10.1104/pp.117.3.979

Queiroz, H. M., Sodek, L., and Haddad, C. R. B. (2012). Effect of salt on the growth and metabolism of Glycine max. Braz. Arch. Biol. Technol. 55, 809-817. doi: $10.1590 /$ s1516-89132012000600002

Rabe, E., and Lovatt, C. J. (1984). De novo arginine biosynthesis in leaves of phosphorus-deficient Citrus and Poncirus species. Plant Physiol. 76, 747-752. doi: $10.1104 /$ pp.76.3.747

Raggi, V. (1994). Changes in free amino acids and osmotic adjustment in leaves of water-stressed bean. Physiol. Plant. 91, 427-434. doi: 10.1034/j.1399-3054. 1994.910311.x

Raman, R. (2017). The impact of genetically modified (GM) crops in modern agriculture: a review. GM Crops Food 8, 195-208. doi: 10.1080/21645698.2017. 1413522

Rare, E. (1990). Stress physiology: the functional significance of the accumulation of nitrogen-containing compounds. J. Hortic. Sci. 65, 231-243. doi: 10.1080/ 00221589.1990 .11516052

Reiter, R. J., Tan, D. X., Zhou, Z., Cruz, M. H., Fuentes-Broto, L., and Galano, A. (2015). Phytomelatonin: assisting plants to survive and thrive. Molecules 20, 7396-7437. doi: 10.3390/molecules20047396

Sairam, R. K., and Tyagi, A. (2004). Physiology and molecular biology of salinity stress tolerance in plants. Curr. Sci. 86, 407-421.

Santa-Cruz, A., Acosta, M., Rus, A., and Bolarin, M. C. (1999). Short-term salt tolerance mechanisms in differentially salt tolerant tomato species. Plant Physiol. Biochem. 37, 65-71. doi: 10.1016/s0981-9428(99)80068-0

Seskar, M., Shulaev, V., and Raskin, I. (1998). Endogenous methyl salicylate in pathogen-inoculated tobacco plants. Plant Physiol. 116, 387-392. doi: 10.1104/ pp.116.1.387

Shah, S. H., Houborg, R., and McCabe, M. F. (2017). Response of chlorophyll, carotenoid and SPAD-502 measurement to salinity and nutrient stress in wheat (Triticum aestivum L.). Agronomy 7:61. doi: 10.3390/agronomy7030061

Sharma, A., and Zheng, B. (2019). Melatonin mediated regulation of drought stress: physiological and molecular aspects. Plants 8:190. doi: 10.3390/plants8070190

Shi, H., Jiang, C., Ye, T., Tan, D.-X., Reiter, R. J., Zhang, H., et al. (2015a). Comparative physiological, metabolomic, and transcriptomic analyses reveal mechanisms of improved abiotic stress resistance in bermudagrass [Cynodon dactylon (L). Pers.] by exogenous melatonin. J. Exp. Bot. 66, 681-694. doi: $10.1093 / \mathrm{jxb} / \mathrm{eru} 373$

Shi, H., Reiter, R. J., Tan, D. X., and Chan, Z. (2015b). INDOLE-3-ACETIC ACID INDUCIBLE 17 positively modulates natural leaf senescence through melatonin-mediated pathway in Arabidopsis. J. Pineal Res. 58, 26-33. doi: 10.1111/jpi.12188 
Sim, H. J., Son, C. W., Liu, X. W., and Kim, M. R. (2008). Green leafy vegetable extracts prevent $\mathrm{Cu} 2+-$ Induced oxidation of human low density lipoprotein. Fed. Am. Soc. Exp. Biol. 22, 889.12-889.12.

Song, F.-N., Yang, C.-P., Liu, X.-M., and Li, G.-B. (2006). Effect of salt stress on activity of superoxide dismutase (SOD) in Ulmus pumila L. J. For. Res. 17, 13-16. doi: 10.1007/s11676-006-0003-7

Su, X., Wu, S., Yang, L., Xue, R., Li, H., Wang, Y., et al. (2014). Exogenous progesterone alleviates heat and high light stress-induced inactivation of photosystem II in wheat by enhancing antioxidant defense and D1 protein stability. Plant Growth Regul. 74, 311-318. doi: 10.1007/s10725-014-9920-1

Takahashi, S., and Murata, N. (2008). How do environmental stresses accelerate photoinhibition? Trends Plant Sci. 13, 178-182. doi: 10.1016/j.tplants.2008. 01.005

Tan, D. X., Hardeland, R., Manchester, L. C., Paredes, S. D., Korkmaz, A., Sainz, R. M., et al. (2010). The changing biological roles of melatonin during evolution: from an antioxidant to signals of darkness, sexual selection and fitness. Biol. Rev. $85,607-623$.

Tatar, Ö, Brueck, H., Gevrek, M. N., and Asch, F. (2010). Physiological responses of two Turkish rice (Oryza sativa L.) varieties to salinity. Turk. J. Agric. For. 34, 451-459.

Tester, M., and Langridge, P. (2010). Breeding technologies to increase crop production in a changing world. Science 327, 818-822. doi: 10.1126/science. 1183700

Thordal-Christensen, H., Zhang, Z., Wei, Y., and Collinge, D. B. (1997). Subcellular localization of $\mathrm{H} 2 \mathrm{O} 2$ in plants. $\mathrm{H} 2 \mathrm{O} 2$ accumulation in papillae and hypersensitive response during the barley-powdery mildew interaction. Plant J. 11, 1187-1194. doi: 10.1046/j.1365-313X.1997.11061187.x

Tsai, Y.-C., Hong, C.-Y., Liu, L.-F., and Kao, C. H. (2005). Expression of ascorbate peroxidase and glutathione reductase in roots of rice seedlings in response to $\mathrm{NaCl}$ and $\mathrm{H} 2 \mathrm{O} 2$. J. Plant Physiol. 162, 291-299. doi: 10.1016/j.jplph.2004. 06.004

Vance, N. C., and Zaerr, J. B. (1990). Analysis by high-performance liquid chromatography of free amino acids extracted from needles of drought-stressed and shaded Pinus ponderosa seedlings. Physiol. Plant. 79, 23-30. doi: 10.1034/j.1399-3054.1990.790104.x

Van Tassel, D. L., Roberts, N. J., and O’Neill, S. D. (1995). Melatonin from higher plants: isolation and identification of N-acetyl-5-methoxytryptamine. Plant Physiol. 108S:101.

Venegas, C., García, J. A., Escames, G., Ortiz, F., López, A., Doerrier, C., et al. (2012). Extrapineal melatonin: analysis of its subcellular distribution and daily fluctuations. J. Pineal Res. 52, 217-227. doi: 10.1111/j.1600-079X.2011.00931.x

Wang, L. Y., Liu, J. L., Wang, W. X., and Sun, Y. (2016). Exogenous melatonin improves growth and photosynthetic capacity of cucumber under salinityinduced stress. Photosynthetica 54, 19-27. doi: 10.1007/s11099-015-0140-3
Wani, A. B., Chadar, H., Wani, A. H., Singh, S., and Upadhyay, N. (2017). Salicylic acid to decrease plant stress. Environ. Chem. Lett. 15, 101-123. doi: 10.1007/ s10311-016-0584-0

Waqas, M., Khan, A. L., Hamayun, M., Shahzad, R., Kim, Y.-H., Choi, K.S., et al. (2015). Endophytic infection alleviates biotic stress in sunflower through regulation of defence hormones, antioxidants and functional amino acids. Eur. J. Plant Pathol. 141, 803-824. doi: 10.1007/s10658-0140581-8

Wei, W., Li, Q. T., Chu, Y. N., Reiter, R. J., Yu, X. M., Zhu, D. H., et al. (2015). Melatonin enhances plant growth and abiotic stress tolerance in soybean plants. J. Exp. Bot. 66, 695-707. doi: 10.1093/jxb/eru392

Whitley, L. (2013). Handbook of Herbs and Spices (2012), 2nd edn, edited by K.V. Peter, Woodhead Publishing Ltd., 80 High Street, Sawston, Cambridge CB22 3HJ, UK. Volume 1 - ISBN 978-0-8570-9039-3, Price $£ 175.00$; Volume 2 - ISBN 978-0-8570-9040-9, Price £170.00. Int. J Dairy Technol. 66, 303-304. doi: 10.1111/1471-0307.12019

Yang, Z., Wang, Y., Wei, X., Zhao, X., Wang, B., and Sui, N. (2017). Transcription profiles of genes related to hormonal regulations under salt stress in sweet sorghum. Plant Mol. Biol. Rep. 35, 586-599. doi: 10.1007/s11105-0171047-x

Zamani, Z., Amiri, H., and Ismaili, A. (2019). Improving drought stress tolerance in fenugreek (Trigonella foenum-graecum) by exogenous melatonin. Plant Biosyst. 154, 1-18. doi: 10.1080/11263504.2019.1674398

Zhan, H., Nie, X., Zhang, T., Li, S., Wang, X., Du, X., et al. (2019). Melatonin: a small molecule but important for salt stress tolerance in Plants. Int. J. Mol. Sci. 20:709. doi: 10.3390/ijms20030709

Zhang, N., Sun, Q., Zhang, H., Cao, Y., Weeda, S., Ren, S., et al. (2015). Roles of melatonin in abiotic stress resistance in plants. J. Exp. Bot. 66, 647-656. doi: $10.1093 /$ jxb/eru336

Zhu, X. F., Wang, B., Song, W. F., Zheng, S. J., and Shen, R. F. (2016). Putrescine alleviates iron deficiency via NO-Dependent reutilization of root cell-wall Fe in Arabidopsis. Plant Physiol. 170, 558-567. doi: 10.1104/pp.15. 01617

Conflict of Interest: The authors declare that the research was conducted in the absence of any commercial or financial relationships that could be construed as a potential conflict of interest.

Copyright (c) 2021 Park, Kazerooni, Kang, Al-Sadi and Lee. This is an open-access article distributed under the terms of the Creative Commons Attribution License (CC BY). The use, distribution or reproduction in other forums is permitted, provided the original author(s) and the copyright owner(s) are credited and that the original publication in this journal is cited, in accordance with accepted academic practice. No use, distribution or reproduction is permitted which does not comply with these terms. 